\title{
WestVirginiaUniversity
}

THE RESEARCH REPOSITORY @ WVU

Graduate Theses, Dissertations, and Problem Reports

2014

\section{Flexure modulus of elasticity in living branch wood}

\author{
Aaron Dwight Carpenter \\ West Virginia University
}

Follow this and additional works at: https://researchrepository.wvu.edu/etd

\section{Recommended Citation}

Carpenter, Aaron Dwight, "Flexure modulus of elasticity in living branch wood" (2014). Graduate Theses, Dissertations, and Problem Reports. 374.

https://researchrepository.wvu.edu/etd/374

This Thesis is protected by copyright and/or related rights. It has been brought to you by the The Research Repository @ WVU with permission from the rights-holder(s). You are free to use this Thesis in any way that is permitted by the copyright and related rights legislation that applies to your use. For other uses you must obtain permission from the rights-holder(s) directly, unless additional rights are indicated by a Creative Commons license in the record and/ or on the work itself. This Thesis has been accepted for inclusion in WVU Graduate Theses, Dissertations, and Problem Reports collection by an authorized administrator of The Research Repository @ WVU. For more information, please contact researchrepository@mail.wvu.edu. 
Flexure Modulus of Elasticity in Living Branch Wood

\title{
Aaron Dwight Carpenter
}

\author{
Thesis submitted \\ To the Davis College of Agriculture, Natural Resources and Design \\ at West Virginia University \\ in partial fulfillment of the requirement for the degree of \\ Master of Science in Forestry \\ Greg Dahle, Ph.D., Chair \\ David DeVallance, Ph.D., \\ Jingjing Liang, Ph.D., \\ Mo Zhou, Ph.D.
}

Division of Forestry and Natural Resources

Morgantown, West Virginia

2014

Keywords: Branch transitions, Biomechanics, Static Force, Flexure modulus, Acoustic Testing Copyright 2014 Aaron Dwight Carpenter 


\section{ABSTRACT \\ Flexure Modulus of Elasticity in Living Branch Wood}

\section{Aaron Dwight Carpenter}

Ever increasing human populations are creating a desire, and more importantly a demand for urban forests due to a disconnection from nature as more of us become urban dwellers. Future trends predict increases in human populations which will substantially increase the amount of urban lands, especially around metropolitan areas. Urban trees are exposed to different loading regimes than similar trees growing in a traditional forest. They do not have protection from wind that is seen in the middle of a forest stand, and wind loading has been suggested as one of the more important modes of failure .

This research investigated how an urban tree withstands environmental conditions and loading during ice, wind, or snow storms. This research is important in terms of preventing cascading effects of localized tree impacts on targets. Flexure modulus of elasticity (MOE) can be defined as an object's tendency to be deformed elastically, or not permanently, when a force is applied to it This research measures flexure modulus distally along the length of the branch as well as identifies key attributes of branch elasticity during different climate periods.

Chapter 2 investigates the potential transitions of MOE of the juvenile pin oak (Quercus palustris) samples using a Dynamic Mechanical Thermal Analysis machine from tree trunk to branch tip. This chapter identifies that there is no difference in branch type (primary or secondary) within the variables of $\mathrm{MOE}$, moisture content percent, slenderness ratio, end diameter, and full length. There is a significant difference between wood densities of the two branch types.

Chapter 3 helps to identify differentiating material properties of flexure MOE of seasonal periodicity between pre-dormant (leaf on) and dormant (leaf off) conditions, as well as temperature fluctuations within seasons. Within each season, half of the samples were frozen to $-6.7 \mathrm{C}$ while the other half were kept at ambient room temperature or $21.1 \mathrm{C}$. Two testing machines were used to measure MOE and subsequently compared to one another. In general, the data obtained from the Fakopp meter calculated MOE higher than the data from the universal test machine (UTM), but had a smaller standard error. The measurements of MOE for temperature and season between the two testing machines were compared and determined to be significantly different using one way analysis of variance of means. When using the UTM and Fakopp, significant differences were found between the cold and ambient temperature, with the cold temperature having a larger MOE. The UTM measured significantly different between seasons, with the dormant season having a higher MOE. 
Chapter 1

Flexure Modulus of Elasticity in Living Branch Wood

Chapter 2

Flexure Modulus Variations Distally along the Branch

- Material and Methods

- Results

- Discussion

- Implications

\section{Chapter 3}

Seasonal and Temperature Periodicity: Transitions of Flexure Modulus in Living Branch

Wood

- Material and Methods

- Results

- Discussion

- Implications

References 


\section{Chapter 1}

\section{Flexure Modulus of Elasticity in Living Branch Wood}

Ever increasing human populations are creating a want, and more importantly a need for urban forests due to a disconnection of urban dwellers from nature. Future trends predict significant human population growth which will substantially increase the amount of urban lands, especially around metropolitan areas (Nowak and Walton 2005; Nowak et al. 2010). The benefits that urban trees provide include helping urban dwellers feel connected to nature, a sense of security, lower energy costs, economic advantages, recreation opportunities, and reduced storm water runoff (Konijnendijk et al. 2006; Nowak et al. 2010). Yet, there are many costs associated with urban trees which include monetary needs for planting, pruning, pest and disease management, mitigating power outages, as well as human health and personal property damage when trees fail (Dwyer et al. 1992; Smiley et al. 2011). Nowak (2005) states that urban forests face various management difficulties due to a close proximity to humans and challenges such as urban development, fire, insect pests, disease, and climactic events. Urban trees have frequent stresses and ecological pressures which arise from limited growing space and adverse weather conditions (Konijnendijk et al. 2006). As the occurrence of frequent extreme climactic events increase due to global climate change, the importance of mitigating urban tree failures before they occur is vital. These climactic events are predicted to increase in both intensity and frequency which can lead to a disruption of critical power services such as the supply of electricity (Field et al. 2012; Field et al. 2014). For example, the Intergovernmental Panel on Climate Change expects temperature extremes to increase, which is correlated with 
climactic extreme events (Field et al. 2012; Field et al. 2014). While urban managers are concerned with the risks associated with tree failures, there has been limited research on how trees withstand environmental loads (James et al., 2014). Thus, the need for a better understanding of how an urban tree withstands environmental conditions and loading during ice, wind, or snow storms is important in terms of preventing cascading effects of localized tree impacts on targets such as critical infrastructure or personal property. A target is considered a person or piece of property, that when impacted can be significantly damaged.

Urban trees are exposed to different loading regimes than similar trees growing in a traditional forest (James et al. 2014). They do not have protection from wind that is seen in a forest stand, and wind loading has been suggested as one of the more important modes of failure (Niklas 2000). Additionally, an open grown tree tends to have a decurrent branching pattern, while forested trees are often associated with a high narrow crown exhibiting excurrent growth due to closed canopy conditions (Hauer et al. 1993; Hauer et al. 2006). It has been suggested that trees which have an excurrent branching pattern exhibit less damage when exposed to static loading, whereas trees which have a decurrent branching pattern tend to display increased breakage due to static loading (Hauer et al. 1993; Hauer et al. 2006). Static loading can be defined as a singular force, or load, acting upon an object. An example of a static load can be snow or ice without wind. A static force will result in a singular deflection of a measurable distance (James et al. 2014). Dynamic loading occurs when two or more forces are acting upon an object. An example of this type of loading can be a combination of ice and wind acting in unison creating torsional effects. A dynamic force will apply the same singular static force, but will augment the deflection creating a larger effect (James et al. 2014). 
Urban foresters and arborists are concerned with being able to predict which trees are at a higher risk of failure (whole tree or branch) which could lead to personal property damage or disruption of electrical services. The consequences associated with the failure of large branches carry higher risks as their failure are more likely to cause substantial damage. The failure of small branches is of limited concern as only minor damage is likely to occur. According to Dahle and Grabosky (2010a), smaller sun branches transition to larger structural branches when a diameter of 2 centimeters is reached. We are interested in learning how branches develop from these smaller sun gathering entities to larger structural type branches ( $>3$ meters in length or 2 centimeters in diameter) (Dahle and Grabosky 2010a; Dahle and Grabosky 2010b). A primary goal is to better understand how branches develop in order to provide valuable insight into tree management activities. Standards from American National Standards Institute, A300-Part 1 (Gilman 2002) suggest that no more than $25 \%$ of the live crown should be removed during pruning activities. Excessive pruning can reduce the amount of energy the tree is able to produce via photosynthesis. ANSI A300 lists various different pruning types; information listed is on pruning to clean, pruning to thin, pruning to raise, and pruning to reduce as these are commonplace within the urban arena. Table 1.1 categorizes the common diameter cuts for each pruning type (Gilman 2002) and suggests that pruning to clean focuses on small structural branches, pruning to thin focuses on sun to small structural branches, pruning to raise focuses on sun branches, while pruning to reduce focuses on sun to medium structural branches. 
Table 1.1: Four common pruning methods with advised cutting diameters as found in ANSI A300.

\begin{tabular}{|l|c|c|c|}
\hline \multicolumn{4}{|c|}{ Pruning Method with Diameter Cuts } \\
\hline Pruning to Clean & Pruning to Thin & Pruning to Raise & Pruning to Reduce \\
\hline \hline $2.5 \mathrm{~cm}$ and larger & $1.5 \mathrm{~cm}-6.5 \mathrm{~cm}$ & $5 \mathrm{~cm}$ and smaller & $2.5 \mathrm{~cm}-10 \mathrm{~cm}$ \\
\hline
\end{tabular}

Thus, young tree pruning should concentrate on sun branches while mature tree pruning should target smaller structural branches without removing fully transitioned branches in which a large amount of carbon resources has been invested and decreasing the chance of decay.

The shift in allometry from a sun to a structural branch appears to coincide with a shift in modulus of elasticity (Dahle and Grabosky 2010b), yet we do not fully understand how this shift is represented. Flexure modulus of elasticity can be defined as an object's tendency to be deformed elastically, or not permanently, when a force is applied to it. Flexure modulus in tension is important in understanding how a tree will resist environmental loading in terms of allowing the end of the branch to bend and bleed off energy. Various pruning cuts could potentially decrease the ability of the branch to bleed off this energy by increasing overall rigidity (Table 1.1). Increases in rigidity and the incurrence of an early winter storm during a pre-dormant season with leaf on conditions, can lead to failure due to loading.

Identifying regions where flexure modulus of elasticity (MOE) transitions from sun to structural branch as well as between dormant and pre-dormant seasons is important in understanding branch stability and guiding proper tree care decisions. This information could provide a better understanding into branch development, in terms of material properties, which is vital in 
selecting specific branches to be removed or managed to guide growth. Branch selection should be based on the understanding that when a portion of the branch is removed there will still be a distinct transition between low and high modulus of elasticity. It is important to the tree that this growth develops into a strong structural branch with a strong connection zone which is less likely to fail regardless of climactic season or temperature.

Trees balance four functions over their lifetime: hydraulics, mechanics, photosynthesis, and reproduction (Niklas 1992) to prevent the over allocation of limited resources (Figure 1.1).

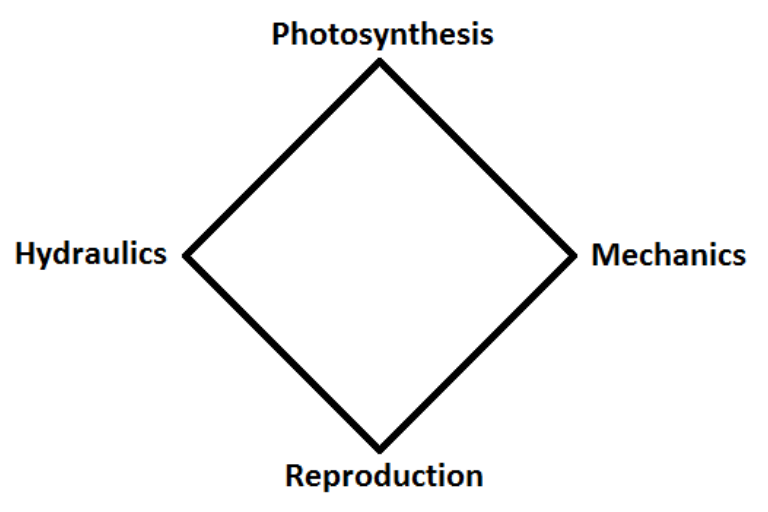

Figure 1.1: Four functions that are balanced during the lifespan of an urban tree. Adapted from Plant Biomechanics: An Engineering Approach to Plant Form and Function (Niklas 1992).

Hydraulics represents the ability to translocate water from the roots to leaves. Water stress causes a reduction in stomata conduction, therefore limiting photosynthesis and growth (Spatz and Bruechert 2000; Niklas 2007). Reproduction is important as a tree will dedicate a significant amount of finite resources to this process (Despland and Houle 1997). A physiologically stressed tree will often respond by apportioning resources to increase reproduction in an effort to pass 
along its genes before death. These resources could otherwise be dedicated to primary (elongation and leaves) or secondary (radial) growth.

Literature often addresses the balance between mechanics and hydraulics, which states that increases in water conduction may lead to decreases in mechanical strength of wood (Kaeiser and Boyce 1965; Ewers 1985; Gartner et al. 1990; Spicer and Gartner 1998; Spicer and Gartner 1998; Wagner et al. 1998; Woodrum et al. 2003; Dahle and Grabosky 2010a). Yet, the balance between photosynthesis and the mechanics of a tree in regards to the growth of an urban tree is likely just as important. Photosynthesis is an essential function as it leads to net primary production and thus creates the energy source that fuels growth. Photosynthesis is correlated to the amount of leaf area in the canopy of a single tree; hence increasing leaf area can be important as trees grow, in terms of increasing the ability to produce more energy for growth. Additionally, there is a mechanical cost to increased amounts of leaves, as there is more surface area for capturing the wind, snow, or ice which can lead to branch or stem failure. A structural branch must be able to mechanically support sun branches or adventitious sprouts which will intercept this energy through leaves and biomass (Niklas 1997; Niklas and Spatz 2000).

Tree growth is determined in part by physiological restrictions such as photosynthesis and water transport (Spatz and Bruechert 2000). As growth adds biomass to branches and increases tree height, mechanics play an important role in preventing failure from self-loading and environmental loads. A sun branch has a lower modulus of elasticity allowing for decreased rigidity when bleeding off energy. A structural branch has a higher modulus of elasticity and is more rigid in order to be able to support numerous sun branches (Dahle and Grabosky 2010a). 
Leaf area and the mechanics of a tree likely have a strong correlation in order to maintain the appropriate photosynthetic capability, a shift in the form and function of a branch can be expected to coincide with the increase in lateral branches. An increase in the number of second order branches can be seen at a diameter of $1.8-2.8 \mathrm{~cm}$ which is found at a branch length of two to three meters (Dahle and Grabosky 2010a). The loss of larger structural branches can substantially decrease photosynthetic capability, due to the number of secondary branches; therefore it is important for a tree to apportion resources to mechanics. Additionally, the loss of larger branches can substantially damage targets, disrupt power, and opens the tree to potential decay organisms and the possibility of localized weakness. Structural branches allocate resources to radial growth to mechanically support numerous sun branches (Dahle and Grabosky 2010a). Mechanical support of branches can come at the expense of physiological functions such as carbon gain and reproduction (Read and Stokes 2006). Hydraulics, reproduction, and photosynthesis are important, but the overarching goal of this research is to understand how growth leads to a mechanically strong branch which is less likely to fail during environmental loading events.

This thesis describes two studies that attempt to fill in knowledge gaps based on flexure modulus of branch wood. Chapter 2 investigates potential variations of flexure modulus axially along the branch based on length of the branch. The flexure modulus may help to determine if there is an influence of branch size on the biomechanics of an urban tree. Chapter 3 identifies dormancy and temperature fluctuations on the material properties of wood. This chapter provides an understanding of how pre-dormant and dormant seasons along with temperature influence bending of an urban tree. 


\section{Chapter 2}

\section{Flexure Modulus of Elasticity Variations Distally along the Branch}

As a branch grows and develops there appears to be a shift in the role from a sun branch to a structural branch. Respective to these two forms, a sun branch will support leaves which captures solar radiation for photosynthesis, and a structural branch provides mechanical support for the sun/subordinate branches (Dahle and Grabosky 2010a).

This study will focus on mechanics of the urban tree and how wood transitions as the branch elongates. A relationship exists between photosynthesis, leaf area, and material properties of the branches supporting the leaves (Farnsworth and Niklas 1995; Niklas 1999). Leaf area, photosynthetic active radiation, and the environment play a large role in photosynthetic capability (Boedhram et al. 2001; Gower 2003). Leaf area varies depending on many attributes which include climate, open canopy/closed canopy, soil type, and hydraulic conductivity. As leaf area increases on a given branch, MOE should increase to provide an adequate amount of rigidity.

It has been shown that branch form and function transitions at around three meters in length from a sun branch to structural branch (McMahon and Kronauer 1976; Bertram 1989; Dahle and Grabosky 2010a), at least in many large shade trees. A flexible sun branch can bleed off energy by bending rather than interception which is important as the higher leaf area is more susceptible to amassing force from loading (Schmidt and Pomeroy 1990). As a branch grows, the number of subordinate branches increase (Dahle and Grabosky 2010a) aggregating the total amount of leaf area per branch (Stephenson et al. 2014). Thus, the increased leaf area amounts 
to a heavier load on primary branches resulting in the need for increased mechanical support. A species with traditionally larger concentrations of leaf area will need more branch support for said leaves on the sun branch. Sun branches are less rigid until they reach the three meter point where the branch assumes a structural role (Dahle and Grabosky 2010a). The structural branch has a higher MOE, thus able to resist larger loads and may be less likely to fail during static or dynamic loading events. Strain is the deformation of a piece of a material per a specific unit of length (Hibbeler 2000). Higher MOE and increased diameter would lead to an increased flexural rigidity, or the force required to bend a non-rigid structure (Landau et al. 2009), that limits bending in structural branches resulting in less strain. When branch diameter is small the amount of load or strain that builds up along the outer edges of the wood is minimal. Yet, when the branch grows in diameter the amount of strain during bending can potentially cause rupture.

Wood and materials in general, which have a low modulus of elasticity and low moment of inertia, allow more bending during loading events in comparison to materials which have a higher modulus of elasticity and higher moment of inertia (Niklas 1997; Dahle and Grabosky 2010a; McLean et al. 2011). Juvenile wood has been shown to have lower wood density, in comparison to mature wood, due to the higher microfibril angle and subsequently lower MOE (Helińska-Raczkowska 1994; Zobel and Sprague 1998; Bao et al. 2001; Plomion et al. 2001; Genet et al. 2013). Wood density is the mass of one unit of volume of a specific material. Typically, the center of the tree or branch will contain juvenile wood that will be surrounded by mature wood as the tree ages (Carter et al. 2005a). 
Mechanical properties are positively related to specific gravity due to an increase in the amount of wood material per unit area (Kretschmann 2010). Wood density is important mechanically because it is considered one of the single most important qualifiers of strength in wood materials (Markwardt and Wilson 1935; Williamson 1984; Kretschmann 2010). Limited research appears to have been conducted on juvenile wood within a tree or tree branches in regards to material and mechanical properties (Plomion et al. 2001; Kretschmann 2010). When examining juvenile and mature wood within the same tree, it should be recognized that mature wood will possess material property characteristics that will be considered normal for the long term life of the tree and therefore safer, whereas juvenile wood material properties are considered to be substandard because of the decreased rigidity and wood density (Panshin 1980; Kretschmann 2010). Mature wood exhibits a higher MOE giving a higher measure of rigidity (Cannell and Morgan 1987). This is a precursor to understanding how wood reacts to static loading events based on MOE and modulus of rupture variations axially along the branch at different spatial lengths across a singular sample. Variations of MOE provide the ability to bend at the tip of the branch where the highest amount of leaf are is located, and be rigid at the base where loading is maximized.

Material properties are known to vary between juvenile and mature wood in trees and particularly in branches (Dahle and Grabosky 2010b). Previous research found a range of values for modulus of elasticity in static bending parallel to grain of 3.89 GPA-28.05 GPA for juvenile wood and 3.85-31.6 for mature wood (Cannell and Morgan 1987; Bao et al. 2001).

It was found that MOE varies axially along Acer platanoides (Figure 2.1). 


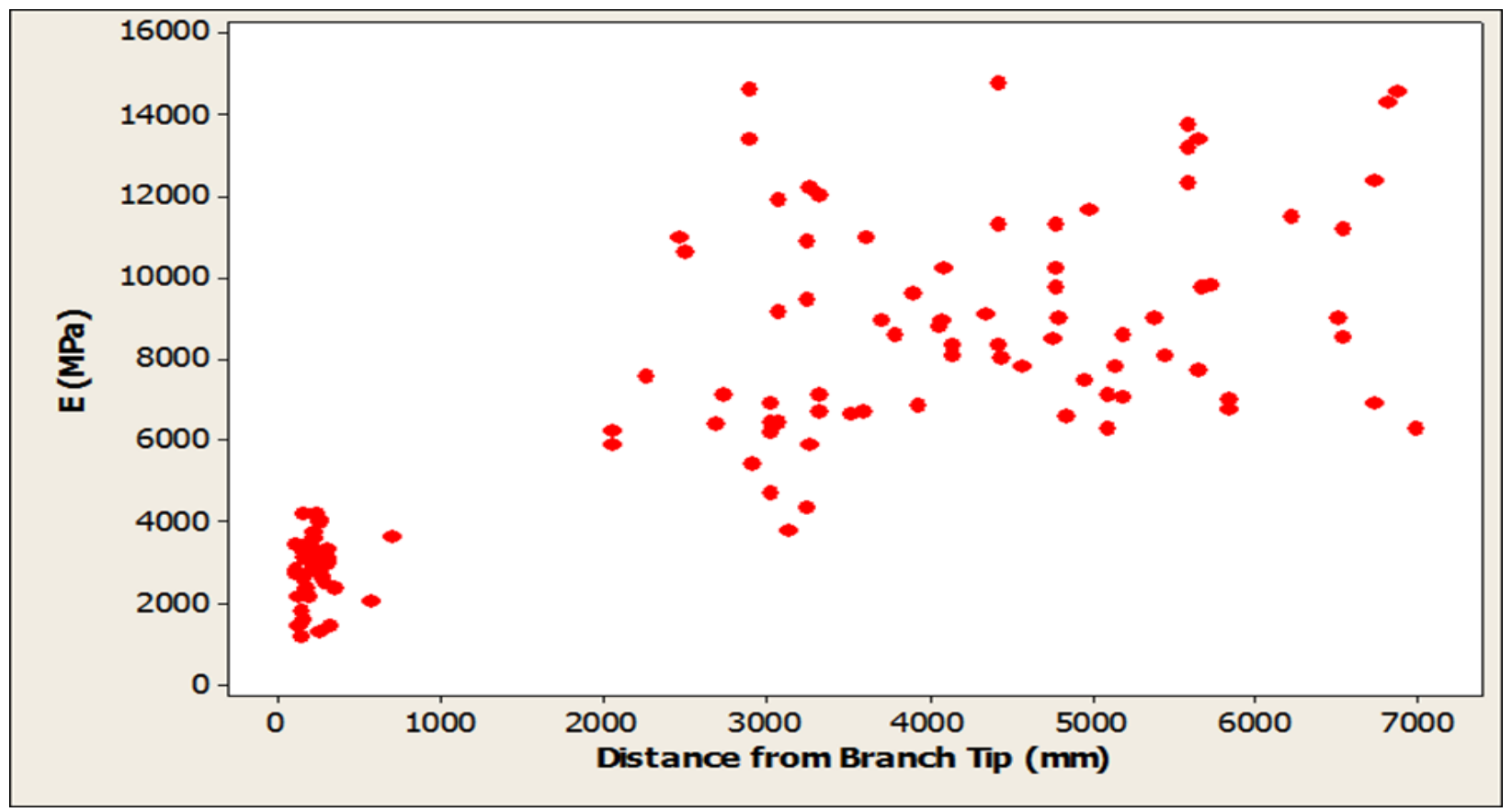

Figure 2.1: Taken from Dahle and Grabosky (2010b), showing the variation of flexure modulus in A. platanoides.

This variation was attributed to the difference between juvenile and mature wood as the MOE near the base of the branches was similar to that of mature wood (Dahle and Grabosky 2010b). There is an absence of information around the $100 \mathrm{~cm}$ to $250 \mathrm{~cm}$ distance and understanding how the wood transition to mature wood may inform pruning standards. Additionally it would be useful to ascertain if branches from other larger shade trees follow the same pattern as seen in A. platanoides. This research measured Flexure modulus along the length of pin oak (Quercus palustris) branches to serve as a comparison to previous research and to attempt to fill in knowledge gaps on how MOE varies during the transition from juvenile to mature wood.

\section{Material and Methods:}

Fifteen pin oak trees (Quercus palustris) growing in a lawn setting on the West Virginia University's Evansdale Campus were sampled. A total of 30 branches were sampled between 
May-July 2013, with an average of two branches per tree removed. Fifteen of the branches had primary connections to the main stem of the tree, or a branch collar connection, while 15 of the branches had secondary connections and were connected to a primary branch (Figure 2.2). For the 30 branches the average diameter measured 2.54 centimeters past the branch connection was 6.06 centimeters while the average length for the primary branch type was $516.67 \mathrm{~cm}$ and secondary branch type was $464.33 \mathrm{~cm}$.

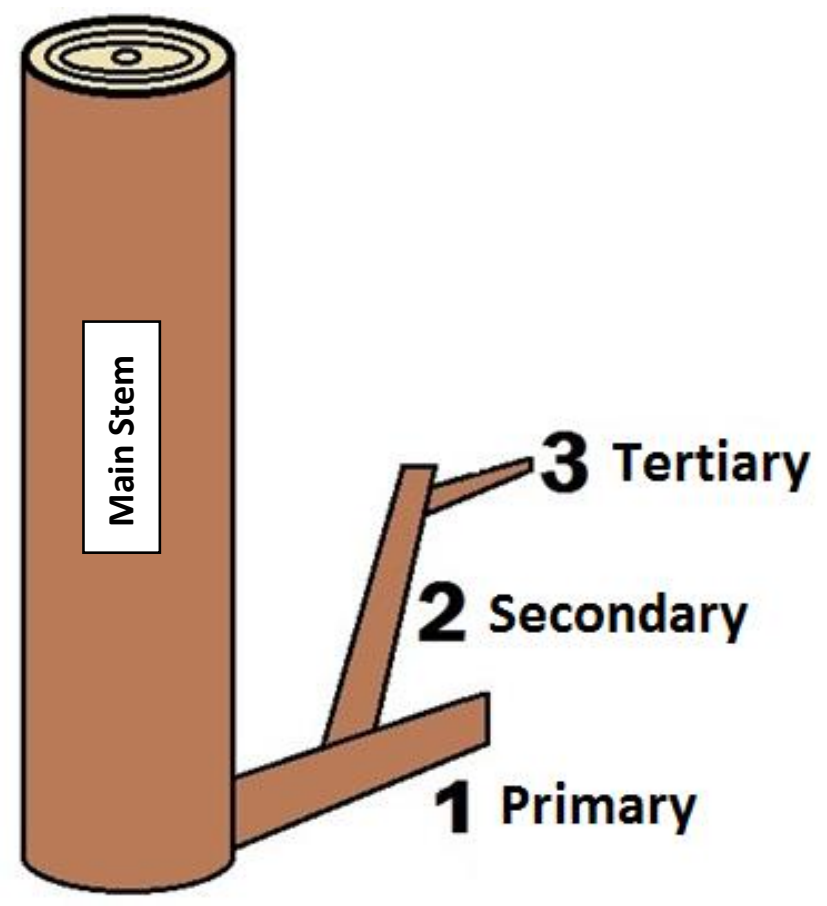

Figure 2.2: A depiction of the branch hierarchal order and how branches are counted based off of the main stem. In this study primary (1) and secondary (2) branches were removed.

The trees were selected based on the number of viable samples, proximity to the West Virginia University campus, and relative good health and branching structure. Primary and secondary structural branches were removed utilizing the three-point cutting method. 
Figure 2.3 depicts a photo of branches similar to those removed for sampling. Branch diameter was measured using digital calipers while branch length was measured using a $150 \mathrm{~cm}$ long string running along the contours of the branch giving exact length.

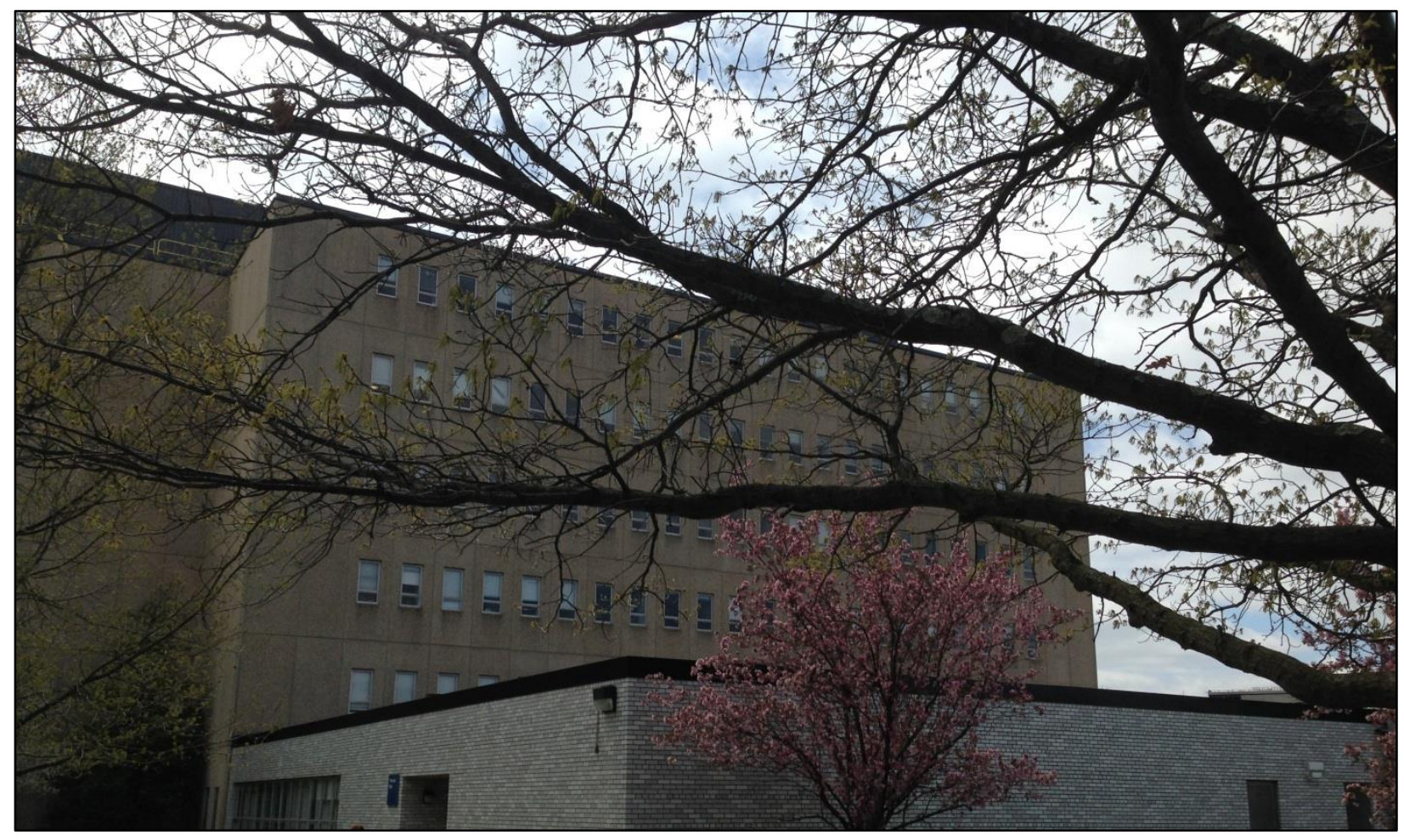

Figure 2.3: A photo showing branches similar to the ones which were removed in this study.

The branches were cut into six sections which represented an exact percentage from which measurements of MOE were taken (Figure 2.4). 


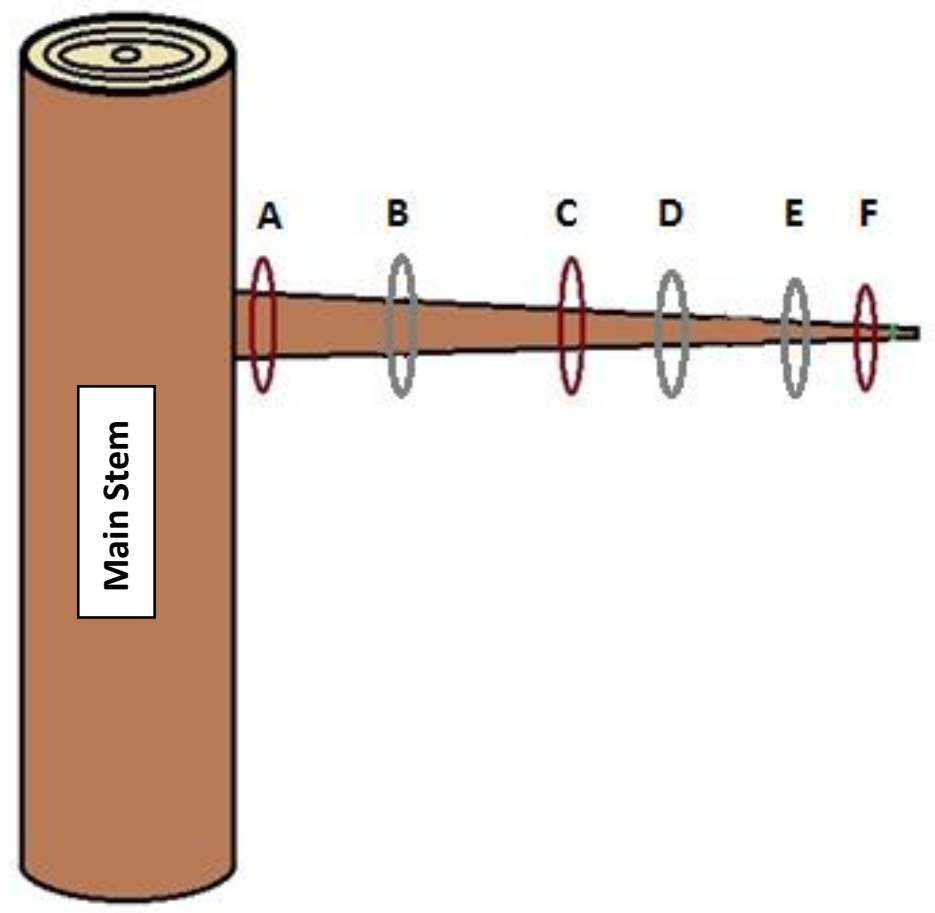

Figure 2.4: Indicates where cuts were made to obtain sections of the structural branch for calculation of modulus of elasticity. Cut A is at $1 \%$ of the length, B is at $25 \%, C$ is at $50 \%, D$ is at $66 \%, \mathrm{E}$ is at $82 \%$, and $\mathrm{F}$ is at $99 \%$.

Cut A was $2.5 \mathrm{~cm}$ distally from the bole of the tree; cut $F$ was $2.5 \mathrm{~cm}$ proximally from the latest bud scar, and cut $C$ was halfway between $A$ and $F$. Cut B was halfway between cut $A$ and $C$ while cuts $\mathrm{D}$ and $\mathrm{E}$ were at the midpoint between cut $\mathrm{C}$ and $\mathrm{F}$. The six sections of each branch were milled down to a maximum of $7.6 \mathrm{~cm}$ in length and $0.64 \mathrm{~cm}$ in width using a band saw (Figure 2.5 and 2.6). 


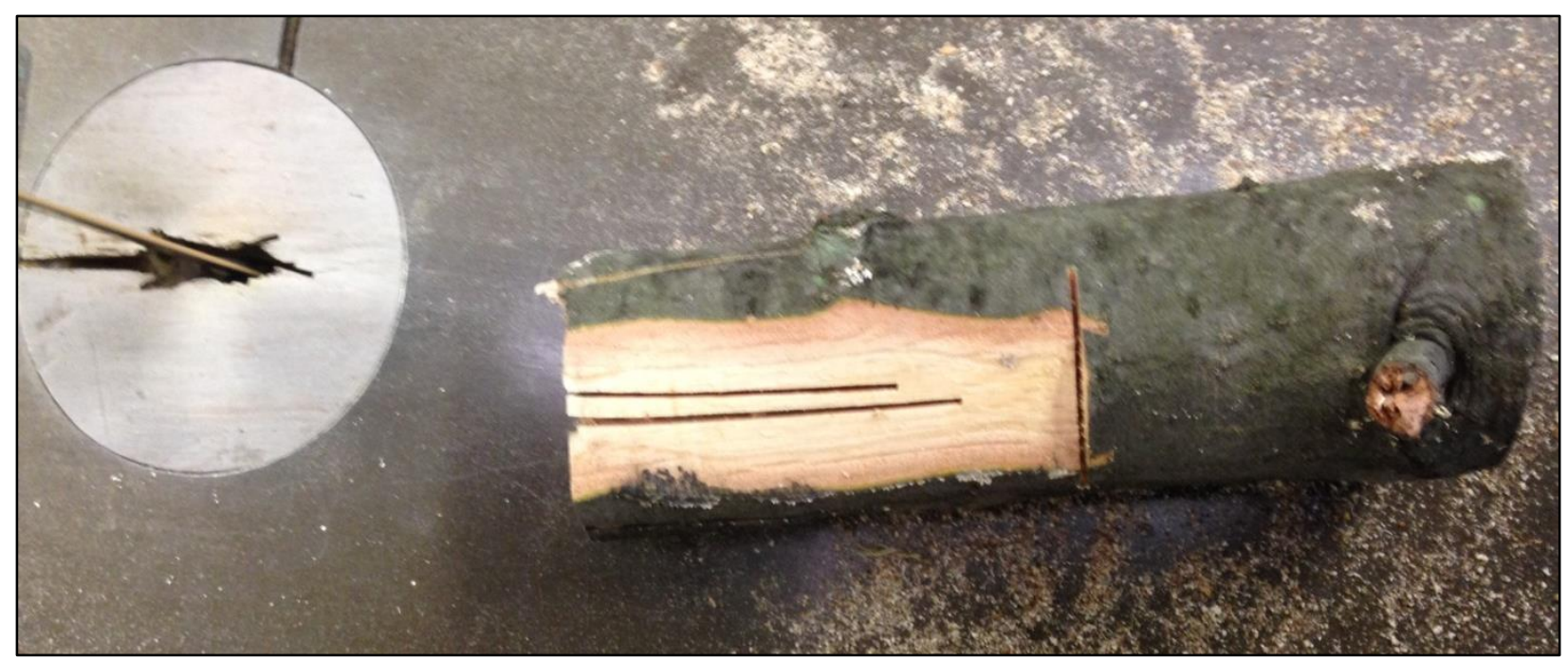

Figure 2.5: A recently milled branch sample, the wood obtained from this will be used for testing Flexure modulus in the DMTA.

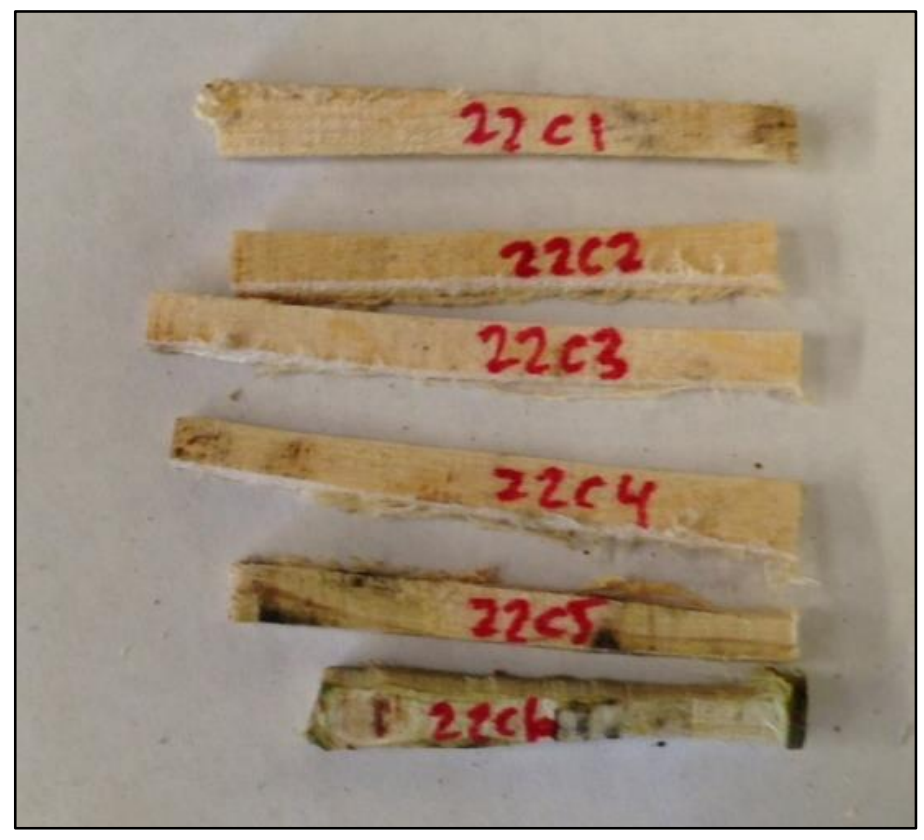

Figure 2.6: Example of the cut samples from branch 22. Variations in length are corrected when using the Flexure modulus equation.

Milling concentrated on the outer growth ring of the proximal sections (A-D) to compare the more recent years with that of section $E$ and $F$ (Figure 2.4). The milled samples provided us with 
the most recent growth and can be an indicator of differentiating material properties. Due to the anisotropic properties of wood, sections were cut in the longitudinal direction and flexure modulus of elasticity in bending was tested parallel to grain using a Dynamic Mechanical Thermal Analysis Machine (DMTA, DMA Q800) for determining MOE (Figure 2.7).

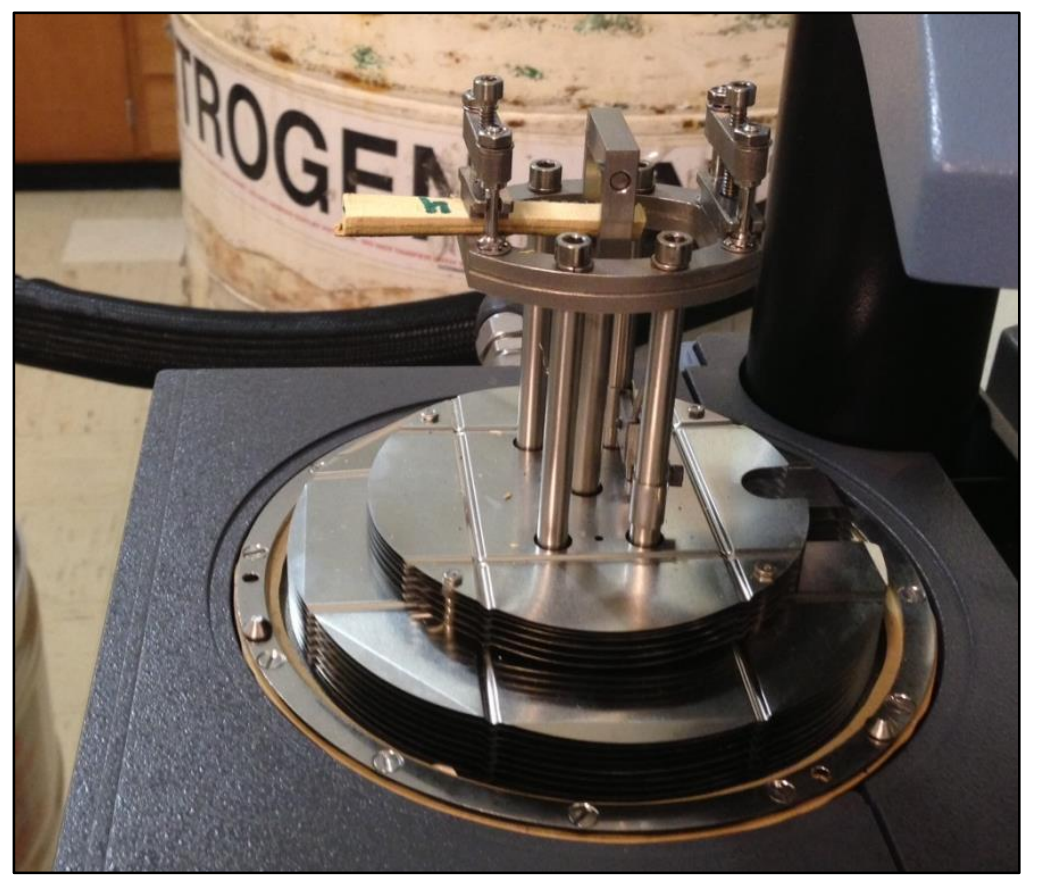

Figure 2.7: A wood sample in the process of being tested using a cantilever test by the Dynamic Mechanical Thermal Analysis machine.

Data from the DMTA was put into the following equation 1 to measure MOE for a cantilever test.

$M O E=\frac{2 * \text { Slope } * \text { Clamp distance lengt } h^{2}}{\text { Base } * \text { Height }^{3}} *((3 *$ Length $)-$ Clamp distacnce length $),($ Equation 1)

- Slope $=$ slope of the linear region taken from the force $(n)$ versus deflection $(\mu \mathrm{m})$ curve.

- Clamp distance length= length of cantilever connection to static force clamp $(2.06 \mathrm{~cm})$ 
- Length= is the overall length of the sample $(\mathrm{cm})$

- $B a s e=$ is the overall width of the sample $(\mathrm{cm})$

- Height= is the overall height of the sample $(\mathrm{cm})$

Slope was found from the linear regression relationship of load $(n)$ divided by deflection $(\mu m)$.

Moisture content percent was measured using the following equation 2. Immediately after samples were statically loaded, they were weighed and then dried in a Fisher Scientific Isotemp 500 series oven at 50 Celsius for 3 days. After the dry down they were immediately weighed and moisture content percent at time of testing was calculated.

Moisture Content \% at time of testing $=\frac{\text { wet weight-dryweight }}{\text { dryweight }} * 100 \%$, (Equation 2) Specific gravity is a unitless measurement and quantifies the amount of wood substance contained in a sample. Modulus of elasticity vary can vary within the same species along with moisture content and specific gravity. Specific gravity was calculated with the following equation 3.

Basic Specific Gravity $=\frac{\text { DryWeight }(\mathrm{g})}{\text { Fresh Volume }\left(\mathrm{cm}^{3}\right) * \text { Density of Water }\left(\frac{\mathrm{g}}{\mathrm{cm}^{3}}\right)}$, (Equation 3)

Slenderness ratio is the ration between full branch length of an individual branch divided by the diameter from cut A for said branch (Table 2.2). This was calculated with the following formula, equation 4:

Slenderness ratio $=\frac{\text { Full Branch Length }(\mathrm{cm})}{\text { End Diameter }(\mathrm{cm})},($ Equation 4$)$ 
Slenderness ratio helps to understand a possible sift in branch form and is valuable in understanding the transitions axially along the branch (Dahle and Grabosky 2010a).

R Studio version 0.98 was utilized for statistical testing methods such as ANOVA, paired t-tests, and linear regression, using $\alpha=0.05$. Modulus of elasticity, moisture content, and wood density were determined to be non-normal, therefore they were transformed using a logarithmic scale for normality. Residual were determined to be normal after using a logarithmic scale.

\section{Results:}

A total of 30 branches, 15 primary and 15 secondary, were removed from 15 trees during the summer of 2013. The average height for the sample trees was $17.8 \mathrm{~m} \pm 1.69$, while the average diameter at $1.4 \mathrm{~m}$ (diameter at breast height) was $46.2 \mathrm{~cm} \pm 0.58$. A one way ANOVA did not identify any significant tree effect on $\operatorname{MOE}(P=0.0881, n=177)$.

Each branch had 6 samples removed from fixed distances represented by various percentages along the branch indicated as cut A-F. The summary statistics for each cut can be found in Table 2.1. 
Table 2.1: The results of six Welch's t tests run to determine if branch type is a significant predictor of MOE based on percentage of branch.

\begin{tabular}{ccccccc}
\multicolumn{7}{c}{ Average Young's Modulus (GPA) \pm SE } \\
by Branch Type \\
Branch Type & $\mathrm{A}(1 \%)$ & $\mathrm{B}(25 \%)$ & $\mathrm{C}(50 \%)$ & $\mathrm{D}(66 \%)$ & $\mathrm{E}(82 \%)$ & $\mathrm{F}(99 \%)$ \\
\hline Primary & $2.81 \pm 0.45$ & $2.43 \pm 0.32$ & $2.02 \pm 0.28$ & $1.94 \pm 0.24$ & $1.81 \pm 0.21$ & $1.46 \pm 0.17$ \\
Secondary & $2.76 \pm 0.41$ & $2.25 \pm 0.31$ & $2.31 \pm 0.27$ & $1.83 \pm 0.24$ & $1.90 \pm 0.20$ & $1.31 \pm 0.16$ \\
P-value & 0.940 & 0.700 & 0.470 & 0.760 & 0.760 & 0.550 \\
$\mathrm{n}$ & 29 & 30 & 30 & 29 & 30 & 29 \\
\multicolumn{7}{c}{ Average Young's Modulus (GPA) \pm SE } \\
Branch Type & $\mathrm{A}(1 \%)$ & $\mathrm{B}(25 \%)$ & $\mathrm{C}(50 \%)$ & $\mathrm{D}(66 \%)$ & $\mathrm{E}(82 \%)$ & $\mathrm{F}(99 \%)$ \\
\hline Primary & $0.93 \pm 0.76$ & $2.15 \pm 0.41$ & $1.57 \pm 0.37$ & $1.75 \pm 0.32$ & $1.66 \pm 0.26$ & $1.30 \pm 0.21$ \\
Secondary & $1.34 \pm 0.60$ & $1.60 \pm 0.45$ & $1.69 \pm 0.34$ & $1.70 \pm 0.29$ & $1.66 \pm 0.23$ & $1.27 \pm 0.17$ \\
P-value & 0.426 & 0.401 & 0.815 & 0.928 & 0.989 & 0.939 \\
$\mathrm{n}$ & 13 & 16 & 18 & 19 & 20 & 24
\end{tabular}

A one way ANOVA was run to examine if branch type (primary or secondary) was a significant predictor of flexure modulus. Results from various t-tests did not identify any statistically significant differences between MOE in primary and secondary branches at each cut location (Table 2.1).

Various one way ANOVAs were run to identify variations between branch types, primary and secondary. There is statistically significant difference in full length between primary and secondary branch $(P=<0.001, n=180)$. There was no statistical difference between end diameter for primary and secondary branch $(P=0.208, n=30)$. Slenderness ration between primary and secondary branch was calculated by the ratio of full length divided by end diameter. There was no statistical difference of the slenderness ratio between branch type $(P=$ 0.263, $n=30$ ). 
Table 2.2: Summary results for the one way ANOVAs run for variations in branch.

\begin{tabular}{|c|c|c|c|}
\hline \multirow[b]{3}{*}{ Explanatory Variable } & \multicolumn{3}{|c|}{ At a Moisture Content of $30 \%$ or greater } \\
\hline & \multicolumn{2}{|c|}{ Differences between } & \multirow{2}{*}{$\begin{array}{l}\text { Interactions between explanatory variable and cut } \\
\text { Combined for all cuts }\end{array}$} \\
\hline & Primary & Secondary & \\
\hline \multicolumn{4}{|l|}{$\overline{\mathbf{x}}$ Full Length $\pm \mathrm{SE}$} \\
\hline$(\mathrm{cm})$ & $516.67 \pm 7.19$ & $464.33 \pm 7.23$ & $490.36 \pm 5.18$ \\
\hline P-value & \multicolumn{2}{|c|}{$<0.001$} & 0.512 \\
\hline & \multicolumn{2}{|c|}{180} & 180 \\
\hline \multicolumn{4}{|l|}{$\overline{\mathbf{x}}$ Diameter $\pm \mathrm{SE}$} \\
\hline \multicolumn{4}{|l|}{ P-value } \\
\hline & \multicolumn{2}{|c|}{0.208} & 0.035 \\
\hline \multirow[t]{2}{*}{$\mathrm{n}$} & \multicolumn{2}{|c|}{30} & 30 \\
\hline & Difference & between & Interactions between explanatory variable and cut \\
\hline Explanatory Variable & Primary & Secondary & At branch connection \\
\hline \multicolumn{4}{|l|}{$\overline{\mathbf{x}}$ Slenderness Ratio } \\
\hline $\pm S E$ & $81.13 \pm 2.93$ & $82.46 \pm 2.93$ & $82.43 \pm 2.01$ \\
\hline P-value & \multicolumn{2}{|c|}{0.263} & 0.517 \\
\hline$n$ & \multicolumn{2}{|c|}{30} & 30 \\
\hline
\end{tabular}

As each sample is represented by a predetermined percentage of the branch, a one-way ANOVA was run to determine the significance of the cuts as an indicator of $\operatorname{MOE}(P=<0.001 n=$ 177), (Table 2.3). The data set used to calculate this ANOVA contains samples which had a moisture content percent of below 30\% or fiber saturation point (FSP) (Figure 2.8 and 2.9). A multiple linear regression (MLR) was run to test if moisture content and density are adequate predictors of $\operatorname{MOE}\left(r^{2}=0.73, P=<0.001, n=177\right)$. The equation developed from this model is as follows: 


$$
\operatorname{MOE}(G P A)=-0.64\left(\frac{\text { Moisture Content } \%}{100}\right)-0.64(\text { Wood Density })+1.97
$$

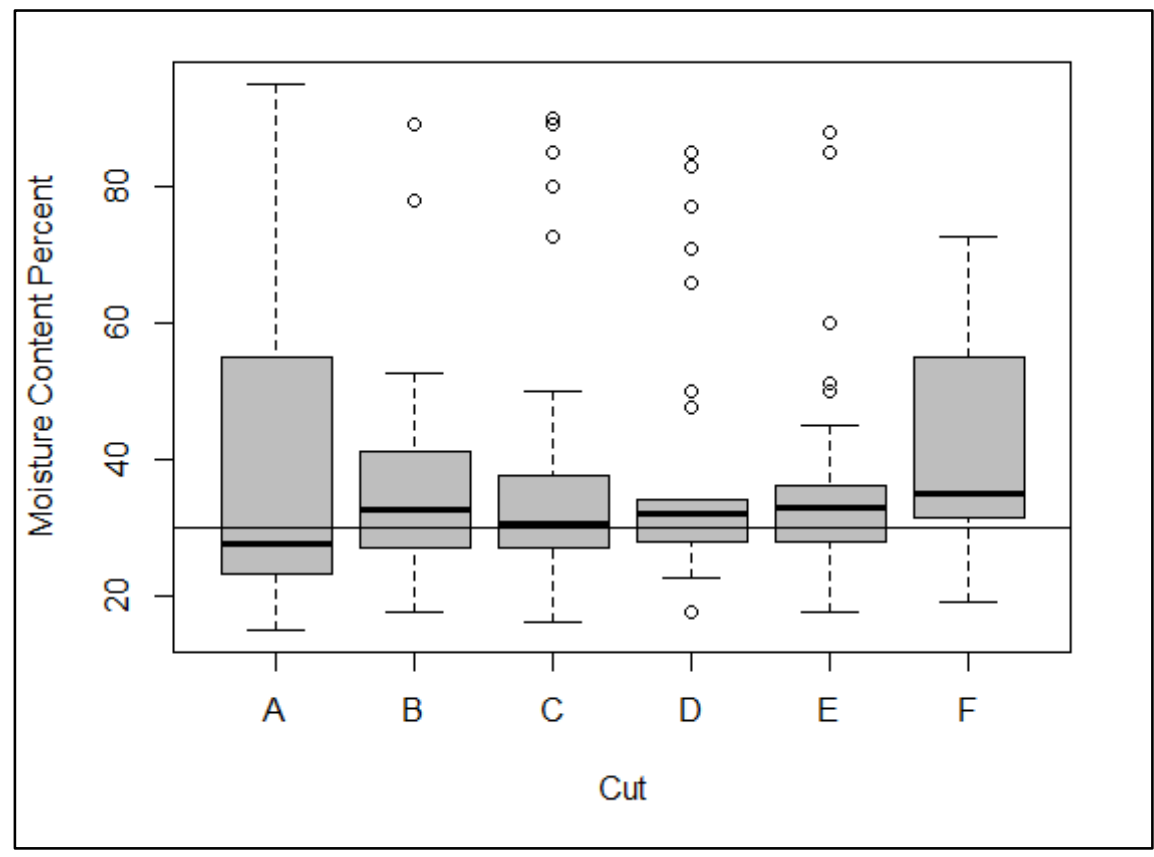

Figure 2.8: Moisture content percent per each cut. The horizontal line indicates a moisture content of the fiber saturation point (FSP) or $30 \%$. 


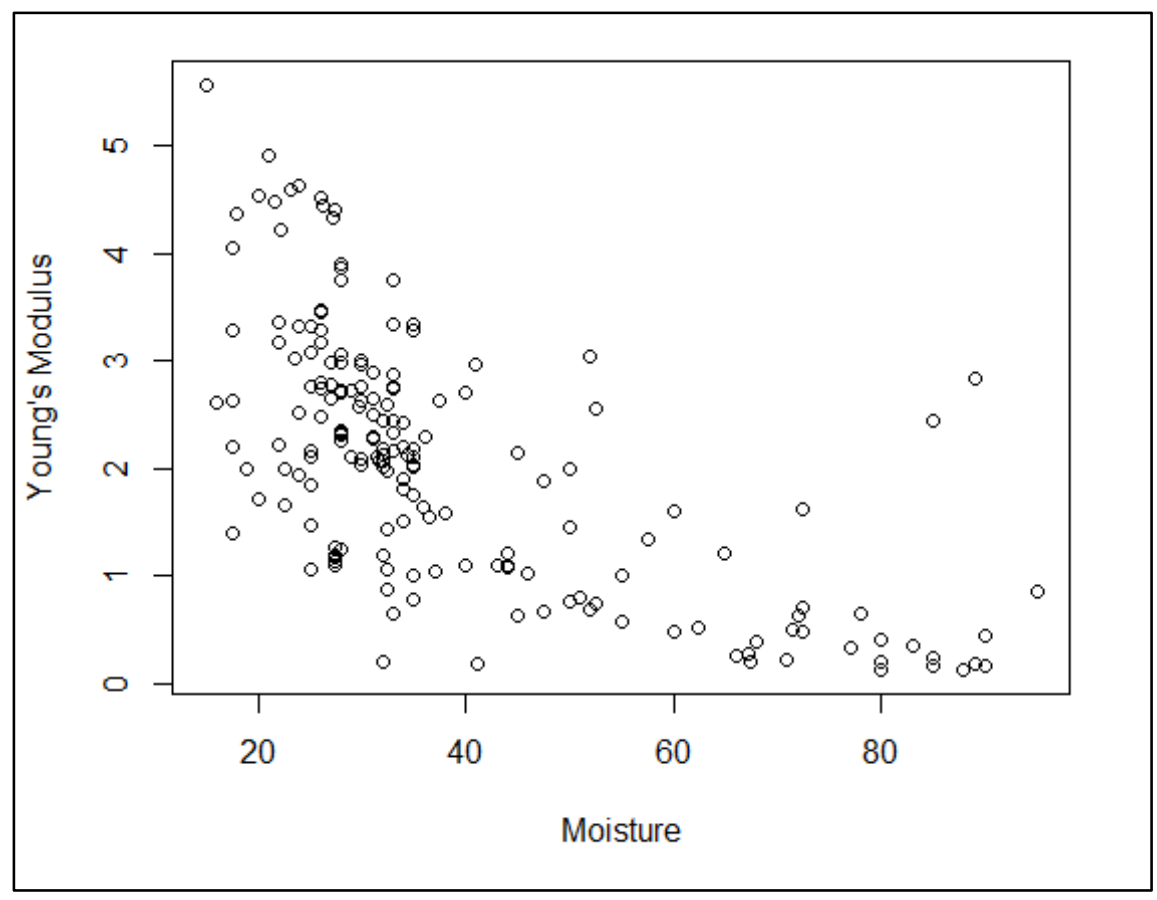

Figure 2.9: A scatterplot visually depicting Flexure modulus by moisture content.

A subset of the data was then created to remove samples below this FSP and the same ANOVA was run $(P=0.237, n=108)$ (Table 2.3). 
Table 2.3: Summary results for various one way ANOVAs run for variations in MOE.

\begin{tabular}{|c|c|c|c|}
\hline \multirow[b]{3}{*}{ Explanatory Variable } & \multicolumn{3}{|c|}{ At a Moisture Content of $30 \%$ or greater } \\
\hline & \multicolumn{2}{|c|}{ Branch } & Interactions between explanatory variable and cut \\
\hline & Primary & Secondary & Combined for all cuts \\
\hline $\begin{array}{c}\bar{x} \text { MOE } \pm \text { SE } \\
\text { (GPA) }\end{array}$ & $1.61 \pm 0.17$ & $1.53 \pm 0.16$ & $1.57 \pm 0.11$ \\
\hline P-value & \multicolumn{2}{|c|}{0.398} & 0.21 \\
\hline$n$ & \multicolumn{2}{|c|}{109} & 109 \\
\hline $\begin{array}{c}\overline{\mathrm{x}} \text { Moisture } \pm \mathrm{SE} \\
(\%)\end{array}$ & $46.41 \pm 2.64$ & $49.25 \pm 2.45$ & $47.93 \pm 1.82$ \\
\hline P-value & \multicolumn{2}{|c|}{0.131} & 0.028 \\
\hline$n$ & \multicolumn{2}{|c|}{109} & 109 \\
\hline $\begin{array}{c}\bar{x} \text { Density } \pm \text { SE } \\
\left(\mathrm{g} / \mathrm{cm}^{3}\right)\end{array}$ & $0.48 \pm 0.13$ & $0.46 \pm 0.12$ & $0.47 \pm 0.05$ \\
\hline P-value & \multicolumn{2}{|c|}{0.766} & 0.049 \\
\hline $\mathrm{n}$ & \multicolumn{2}{|c|}{109} & 109 \\
\hline $\begin{array}{c}\overline{\mathbf{x}} \text { Specific Gravity } \pm \\
\text { SE }\end{array}$ & $0.70 \pm 0.04$ & $0.72 \pm 0.03$ & $0.71 \pm .02$ \\
\hline P-value & \multicolumn{2}{|c|}{0.931} & 0.311 \\
\hline $\mathrm{n}$ & \multicolumn{2}{|c|}{109} & 109 \\
\hline
\end{tabular}

A second ANOVA was run to identify the significance of wood density of the cuts $(P=<0.001$, $n=177)$ as well as determine if there was a difference between branch type $(P=<0.001, n=177)$. Utilizing wood density to calculate wood specific gravity of the samples can be seen in Table $2.3,(P=<0.001, \mathrm{n}=177)$ as well as comparing the specific gravity between branch types ( $P=$ $0.287, n$ 177). 


\section{Discussion:}

As the occurrence of frequent extreme climactic events (Field et al. 2012; Field et al. 2014) and the steady increase of human populations to large metropolitan areas occur (Nowak and Walton 2005; Nowak et al. 2010; Field et al. 2012), a better understanding of how tree branches withstand environmental conditions is very important. The material properties of living wood were analyzed in an attempt to learn how variations in Flexure modulus of elasticity affect the rigidity of a branch. The modulus of elasticity will articulate to an urban forest manager or arborist how a branch will bend up to the point of failure leading to proper tree care techniques.

It is apparent from these results that the branches which were removed during this research had not reached a point of maturity based on modulus of elasticity (Table 2.1 and 2.3) as there was not a difference between MOE at the tip and the base. Kretschmann (2010) lists the MOE for mature pin oak wood as 9.1 GPA for green wood and the highest mean MOE was at location A at 2.78 GPA. While there appears to be an increasing trend in MOE from the tip to the base (cut F-A, Table 2.1, and $600 \mathrm{~cm}$ to $0 \mathrm{~cm}$ in Figure 2.10) this trend was not significant. 


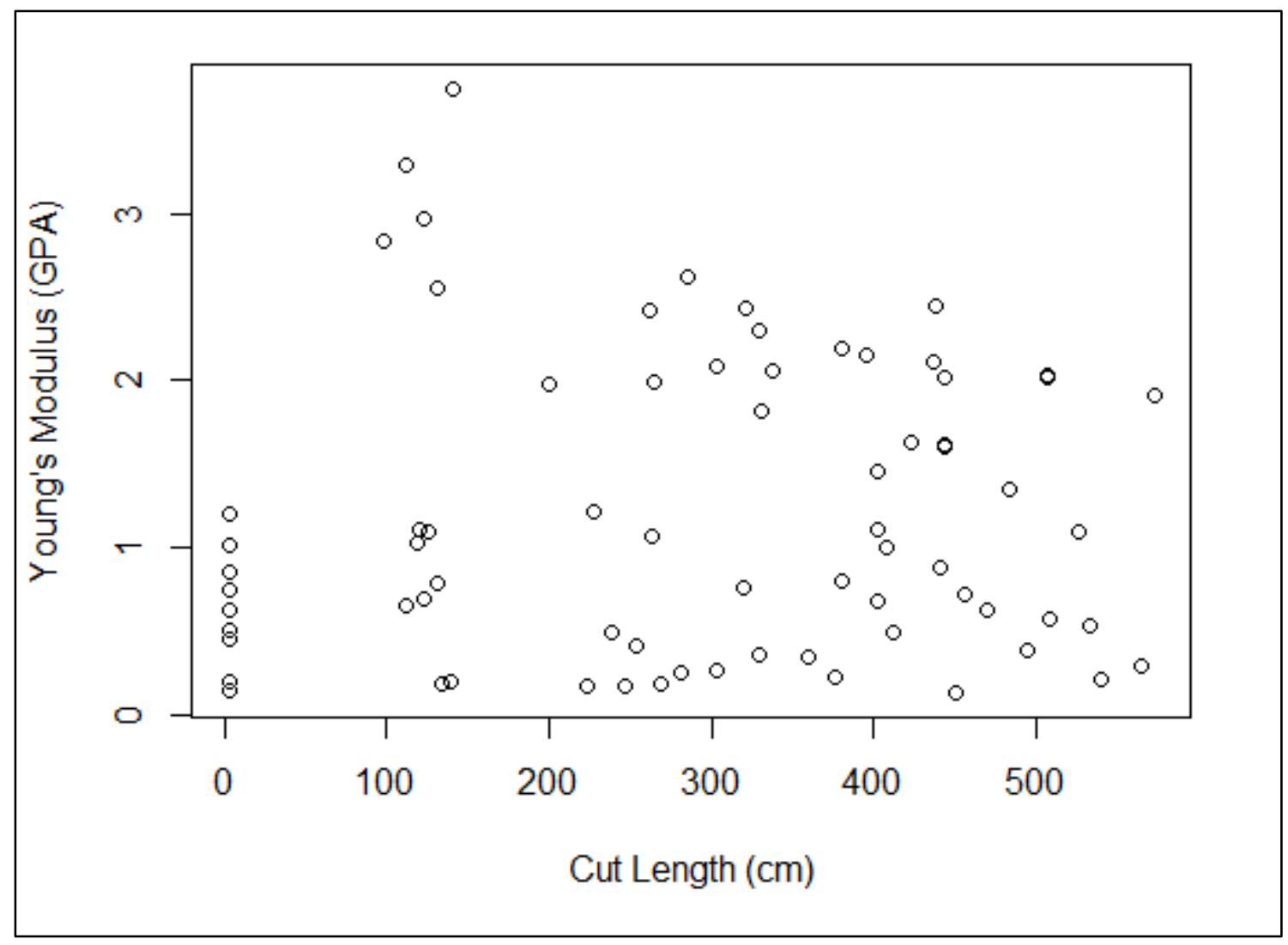

Figure 2.10: A scatterplot visually describing Flexure modulus by cut length. Samples which were at or above fiber saturation point are displayed on this plot.

This trend may suggest that our branches were in the earlier stages of transition into mature wood, yet additional research would need to be conducted for this to be determined. While information on the nature of juvenile wood in $Q$. palustris was not found in the literature, it appears that the transition from juvenile to mature wood in the genus Quercus may not be complete until the ages of 25-30 years (Helińska-Raczkowska 1994). This suggests that simply using allometric data to infer material properties may not always be acceptable. Researchers may wish to find quick non-destructive measures to determine MOE, such as acoustic technology. 
A one way ANOVA compared all of the cut data to analyze the relationship between cut A-F and branch type on MOE. The results indicated that branch type was not a significant predictor of MOE. Welch's t-tests per each cut were conducted to determine if anywhere along the branch indicates branch type. Again, as seen in Table 2.1, MOE did not vary by branch type for any given cut. These results are important when identifying branches to remove during management activities. If provided with the choice between removing a primary or secondary branch, the management decision should not be based on whether the branch connects directly to the tree. A photo displaying branching hierarchy within pin oaks can be seen in Figure 2.11. 


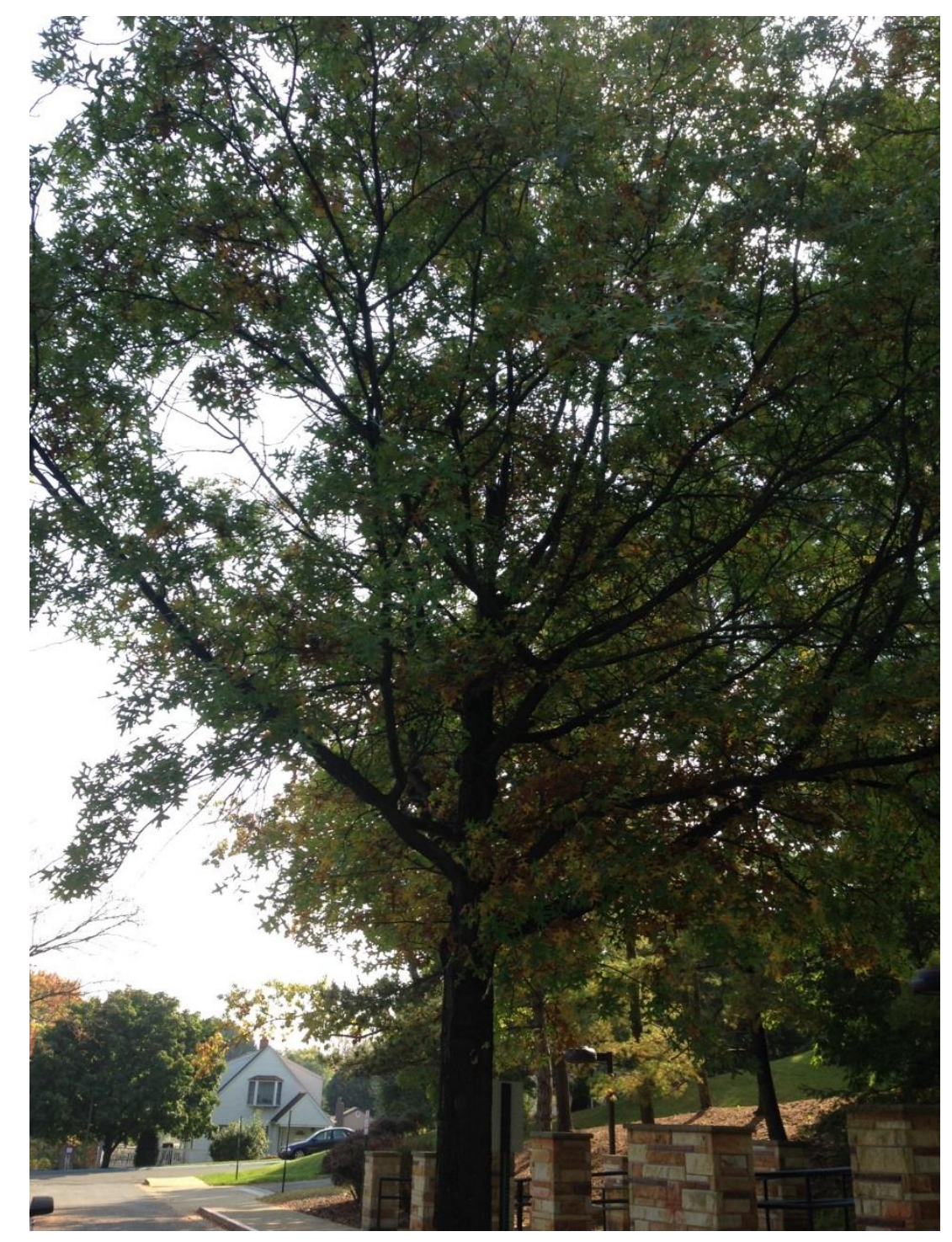

Figure 2.11: Close-up of the crown of a sampled pin oak. Note the branch hierarchy and different branch orders.

Instead the decision should be based on inherent defects and poor connection types because in reality the secondary branch may be a better choice to preserve.

Moisture content percent ranged from 15 to 95 percent as seen in Figure 2.8 and 2.9, and it was determined that moisture content percent did not vary between branch types (Table 2.3). 
The USDA Wood Handbook (2012) lists fiber saturation point at a moisture content of $30 \%$ or lower (Kretschmann 2010). Samples were cut and then weighed with minimal lapse time, yet $38 \%$ of the samples tested were below fiber saturation point. The lower moisture contents can be attributed to the loss of moisture due to indoor environmental cues, the outdoor relative humidity, or the time between milling and weighing. Samples which were calculated to be below FSP were removed from the population. As a result, 69 samples were removed because of inadvertent dry down and branch percent was determined not to be significantly different within the branch.

Wood density was found to vary between branch type and location along each branch (Table 2.3). Density is often a good predictor of mechanical properties of wood and is related to the support against self-loading (gravity), wind, snow, and other environmental loading regimes (Niklas 1992; Hacke et al. 2001; Kretschmann 2010). A multiple linear regression model found that moisture content percent and wood density was the best predictor of MOE in these apparently juvenile branches. This model explains $73 \%$ of the variation between the samples and these two factors are commonly strong predictors (Kretschmann 2010). Our data did not find the location along the branch to explain the variation in $\mathrm{MOE}$, since there was little variation axially along the branches it was not a significant factor in MOE. Yet in the past, the axial position has been found to be an important factor in A. platanoides branches of similar size which had an average age of 14 years (Dahle and Grabosky 2010b), yet these branches has already transitioned to mature wood. Thus an importance of maturity has not been fully ascertained in urban branches. 


\section{Implications:}

The results from this study are important in fostering our understanding of spatial branch transitions. Proper pruning techniques are meant to guide the development of urban trees by augmenting and directing growth to prevent target impacts. It is becoming apparent that the position in the crown is not the governing factor in which branch is at risk of failure. Pruning should concentrate on smaller sun branches rather than larger structural branches. While we understand that allometry of branches may be a good indicator of branch stability, it remains unclear how material properties vary along branches especially in terms of the transition from juvenile to mature wood. This study has shown that this transition most likely takes place different ages in various species. Understanding general patterns of aging may be useful in learning how whole trees deal with environment loads. Indeed understanding when rigidity increases could explain how a branch dampens environmental loads such as wind.

Finally, moisture content of the samples should be controlled in future studies as moisture content is a variable that directly changes the MOE of wood materials. Samples should be kept hydrated immediately after milling down, as well as during all stages of the study to prevent the natural drying process. This will prevent the possibility of varying moisture contents between weighing and the subsequent measuring of Flexure modulus. 


\section{Chapter 3}

\section{Effect of Dormancy and Temperature on Flexure Modulus in Developing Sprouts}

In many forests, particularly higher elevations, trees are exposed to the largest amount of bending forces during the annual dormant period correlated to windthrow and stem breakage (Harris 1992; Valinger et al. 1995). The presence of leaves in a transitional season between predormant (before leaf drop) and dormant stages (after leaf drop) can be concerning if an unseasonal snow or ice storm arrives. Leaf on conditions, during pre-dormant stages, will intercept an increased amount of weight compared to trees during the dormant stage. This load could exacerbate the mechanical stresses along the branch especially at the base. Mechanical loading is thought to be higher during the winter months due to the possibilities of static loading from snow and ice coupled with dynamic loading and a higher wind frequency (Valinger et al. 1995). This is evident in the amount of damage from two successive years of early snow storms in the eastern US; 2011 October nor'easter, and Super Storm Sandy in Oct 2012. As storms are postulated to increase in intensity and frequency based on global climate change, this is a troubling realization (Field et al. 2012). Not only can we expect increased property damage, such climactic events will likely lead to power outages that are wide spread and longer in duration (Field et al. 2012; Field et al. 2014) equal to or greater than outages witnessed during the storms in October 2011 and 2012 storms.

Between 1949-2000, the northeast region United States received 39 catastrophic ice storms incurring an average monetary damage of $\$ 124$ million dollars (Changnon 2003). Ice and freezing rain concern the utility industry based on the weight of the ice on wires and 
transmission towers and the potential of impact from trees (Changnon 2003). The Intergovernmental Panel on Climate Change (IPCC) states with high confidence that risk due to extreme climactic events on services such as electric services based on irreversibility of impacts, timing of impacts, and persistent vulnerability to risks (Field et al. 2014). Indeed this issue is a direct concern to the arboriculture industry as the 2012 Urban Tree Biomechanics Research Summit listed seasonality and temperature as a priority research in understanding potential tree failures.

Green wood typically has lower material properties compared to dried wood that is used as a construction material (Kretschmann 2010), yet little is known how the annual process of dormancy affects material properties of deciduous trees. Seasonality of trees, and in particular how dormancy leads to variations in material properties of wood, needs to be quantified. An understanding of how cambial growth enters a dormant stage during cold winter months and an active stage in the warm summer months, based on resource accumulation, is important in further understanding material properties of trees.

Additionally, knowledge on how ambient temperature affects branch wood material properties is based, for the most part, on construction grade lumber and commercially important tree species. Temperature and availability of precipitation are major factors which hinder plant performance (Harris 1992). It is well known that essentially all mechanical properties of wood increase as temperature and moisture content decrease (below fiber saturation point) (Gerhards 1982), but it is not well understood how temperature impacts material properties of green wood (moisture content $>30 \%$ ). 
The most critical periods for potential tree damage occur during spring and autumn due to rapid temperature fluxes and frost potentials, and the coldest portions of winter correlated with tree hardiness (Harris 1992). Branches that have a large number of lateral sun branches and are described as drooping, are prone to failure under increased snow or ice loads in areas that are not at high altitudes (Cannell and Morgan 1989). Additionally, seasonal temperature fluctuations above and below the freezing of wood provide the opportunity for internal shake damage of urban trees (Harris 1992). Hence, it is important to create a base of knowledge of how seasonal changes affect the material properties of wood in regards to modulus of elasticity, temperature fluctuations, and branch failures.

For a static load to incur damage, the force on the branch must increase to a point which exceeds the proportional limit. When initial failure occurs there is a physical change in the region of the branch indicated by an abrupt transition from the elastic zone into the plastic zone in which the wood will not return to normal position. Decreases in air temperature and light winds are considered favorable conditions for a common static force to occur in the form of snow accumulation (Nykänen et al. 1997). According to Gerhards (1982) and Kretschmann (2010), mechanical properties of wood decrease when heated and increase when cooled. Temperature tends to have greater effects on MOE at higher moisture contents (greater than $30 \%$ or above fiber saturation point) which are more apparent during cold temperatures than warm temperatures (Gerhards 1982; Hogan and Niklas 2004; Kretschmann 2010). This is important in understanding how the branch wood may react to static loading depending on outside environmental cues such as temperature and lead to an increase or decrease in the likelihood of failure. 
Published material properties are useful in understanding general trends in the mechanical nature of a given species (Niklas 1992; Spatz and Bruechert 2000; Plomion et al. 2001; Read and Stokes 2006; Dahle and Grabosky 2009; Kretschmann 2010; Dahle and Grabosky 2010a). While measurement of MOE typically have high coefficients of variation, ascertaining how MOE is impacted by temperature or seasonality can be useful in understanding how branches and trees withstand loading events.

While laboratory testing can determine $\mathrm{MOE}_{S}$ (static MOE), it requires destructive sampling and therefore only useful after a tree or limb has been removed. Acoustic testing can be used to estimate the density and dynamic $\mathrm{MOE}\left(\mathrm{MOE}_{\mathrm{D}}\right)$ of wood, by measuring the speed of sound through a sample of wood (Downes and Drew 2008; Kretschmann 2010) without the need for destructive sampling. Research has led to the understanding that acoustic velocity is an accurate predictor of modulus of elasticity of wood that is derived from standing trees (Gao et al. 2013). Stress wave relationships between sawn logs and lumber have shown that the modulus of elasticity of the log correlates well to the average modulus of elasticity of the lumber (Ross et al. 1997).

Gao et al. $(2012,2013)$ found that wood temperature had a significant effect on how acoustic sound travel through clear wood in standing trees. As the temperature of wood reaches freezing, as found in the winter season, velocity of sound waves increase as temperature decreases (Gao et al. 2012; Gao et al. 2013). The speed of sound slowly decreases as branch wood warms above freezing and as moisture content increases (Bächle and Walker 2006; Kretschmann 2010). Though branches tend to include small imperfections, such as knots, the 
one-way flight path of the stress wave timer will circumvent these areas reasonably well (Chauhan and Walker 2006).

Sound wave technology has been used in fields for nondestructive materials resonance testing as an indicator of material properties (Vary and Lark 1978; Vary and Bowles 1979; Henneke et al. 1986; Halabe et al. 1997). In standing trees, advanced sound wave technology is used to measure rot which cannot be seen from the outside of the tree (Gilbert and Smiley 2004). This allows for the testing of flexure modulus of live trees, but comes with a large cost associated with the equipment and a lengthy setup due to the number of sound probes. Stress wave timers, such as the Fakopp used in this study, allow for simplistic sound wave stress tests of living trees and prevent the need for destructive sampling. A combination of visual testing a single-path testing machine is relevant in the justification of additional tests which can predict internal defects (Wang and Allison 2008).

This research aims to identify how seasonal periodicity (pre-dormant and dormant) affects the material properties of wood. How temperature fluctuations affect material properties within and between seasons. Additionally, the research evaluated whether the two techniques used to measure Flexure modulus (sound wave density and universal test machine) were significantly different from each other.

\section{Material and Methods:}

Sample trees were growing at West Virginia University's Research Forest, located in Monongalia County, West Virginia. The site chosen was a 74 acre, completed 3-stage 
shelterwood cut. The regrowth trees were all naturally regenerated stump sprouts which can be considered similar to regrowth occurring after storm damage or heading cut. An urban tree tends to have a decurrent shape due to an open canopy while a forested tree tends to have a high narrow crown exhibiting excurrent growth due to closed canopy conditions (Hauer et al. 1993; Hauer et al. 2006; DeVallance et al. 2011). These trees are used to theoretically mimic branch wood on larger urban trees based on their open grown conditions.

A total of 120 northern red oak (Quercus rubra) trees were cut, 60 in the active pre-dormant stage, and 60 in the dormant stage (Figure 3.1 and 3.2). 


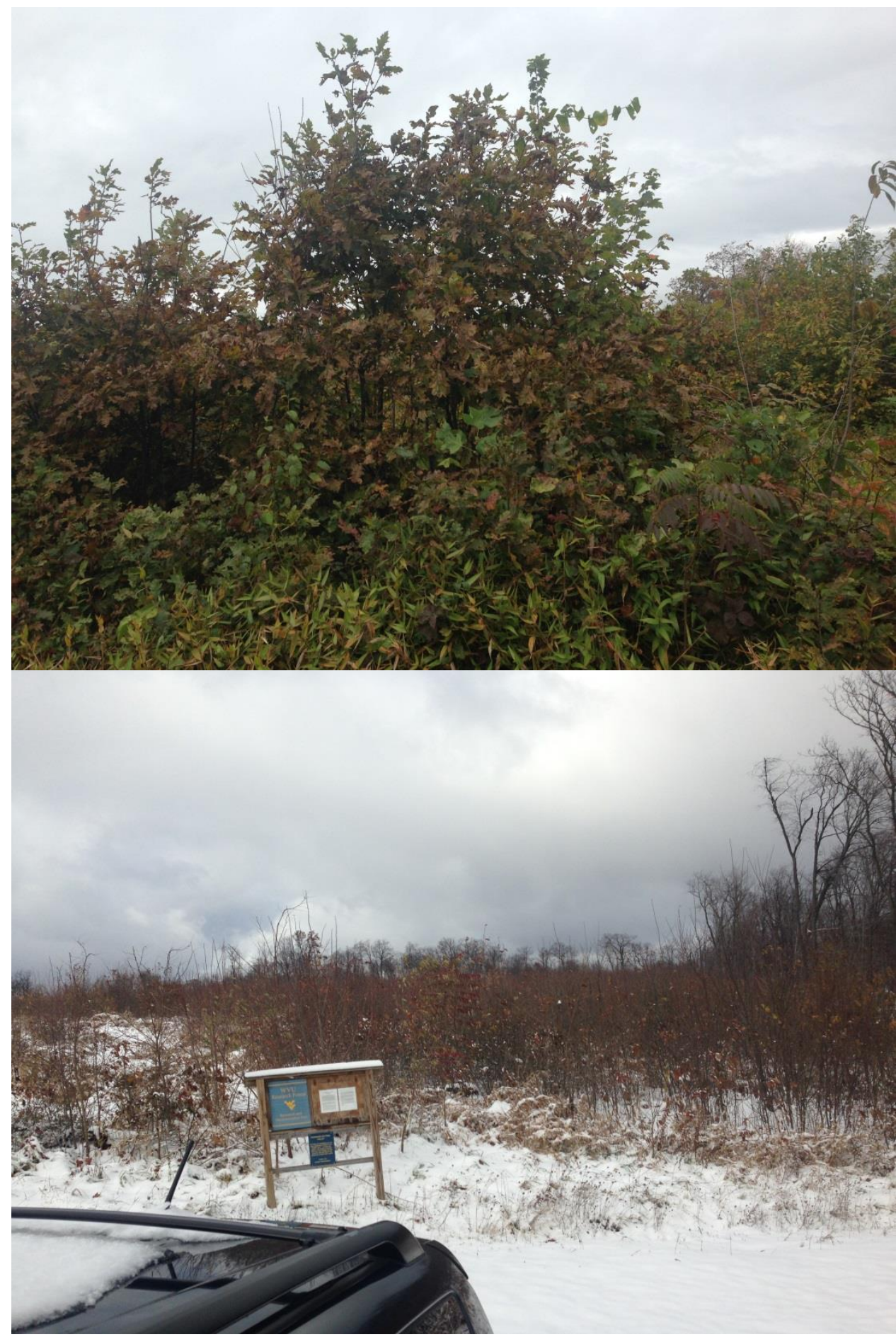

Figure 3.1: Location of sampling during different seasons, pre-dormant (leaf on) and dormant (leaf off). 


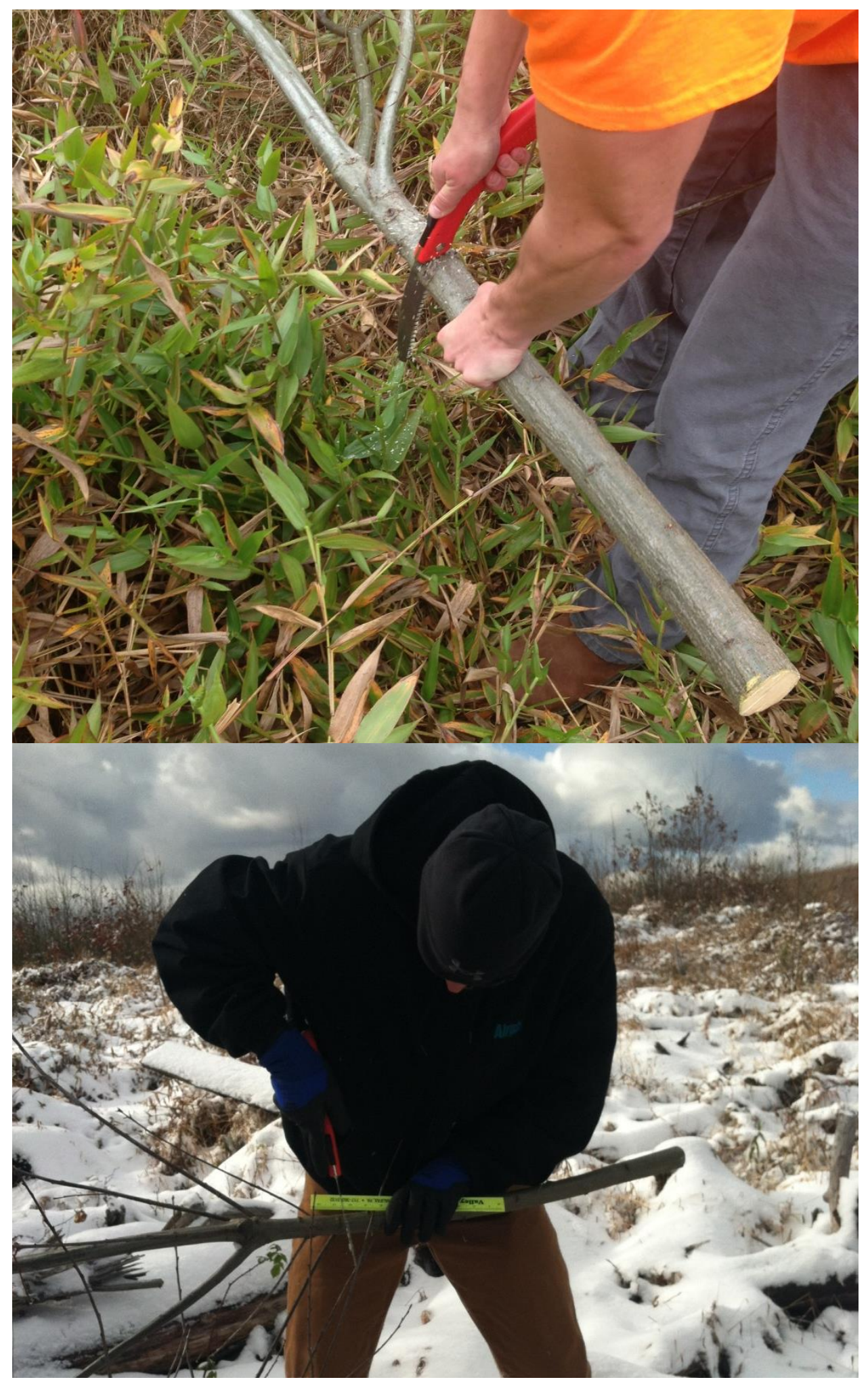

Figure 3.2: Different sampling conditions between pre-dormant (top picture) and dormant conditions (bottom picture). 
Pre-dormant samples were taken in September 2014, while dormant sampling was conducted during February 1st through February 8th in 2013. The stump sprouts had no more than one stem being removed for every stump to mimic naturally mortality and to spread the sample population out to multiple stumps. For each sampling season 60 sprouts were randomly separated into two equal groups. Thirty of the sprouts were placed at ambient room temperature, estimated at 21.1 Celsius for five days and the other half were placed in a CSZH/AC unit at -6.7 Celsius for five days. Each tree had a 55.9 centimeter length sample cut from the stump; the bottom, middle, and top diameter were measured for elasticity calculations. First $\mathrm{MOE}_{\mathrm{D}}$ was calculated using the Fakopp Microsecond Timer by determining the time it takes for a sound wave, caused by a hammer tap on an electrode, to reach the end of each sample and back to the starting position (Figure 3.3). 


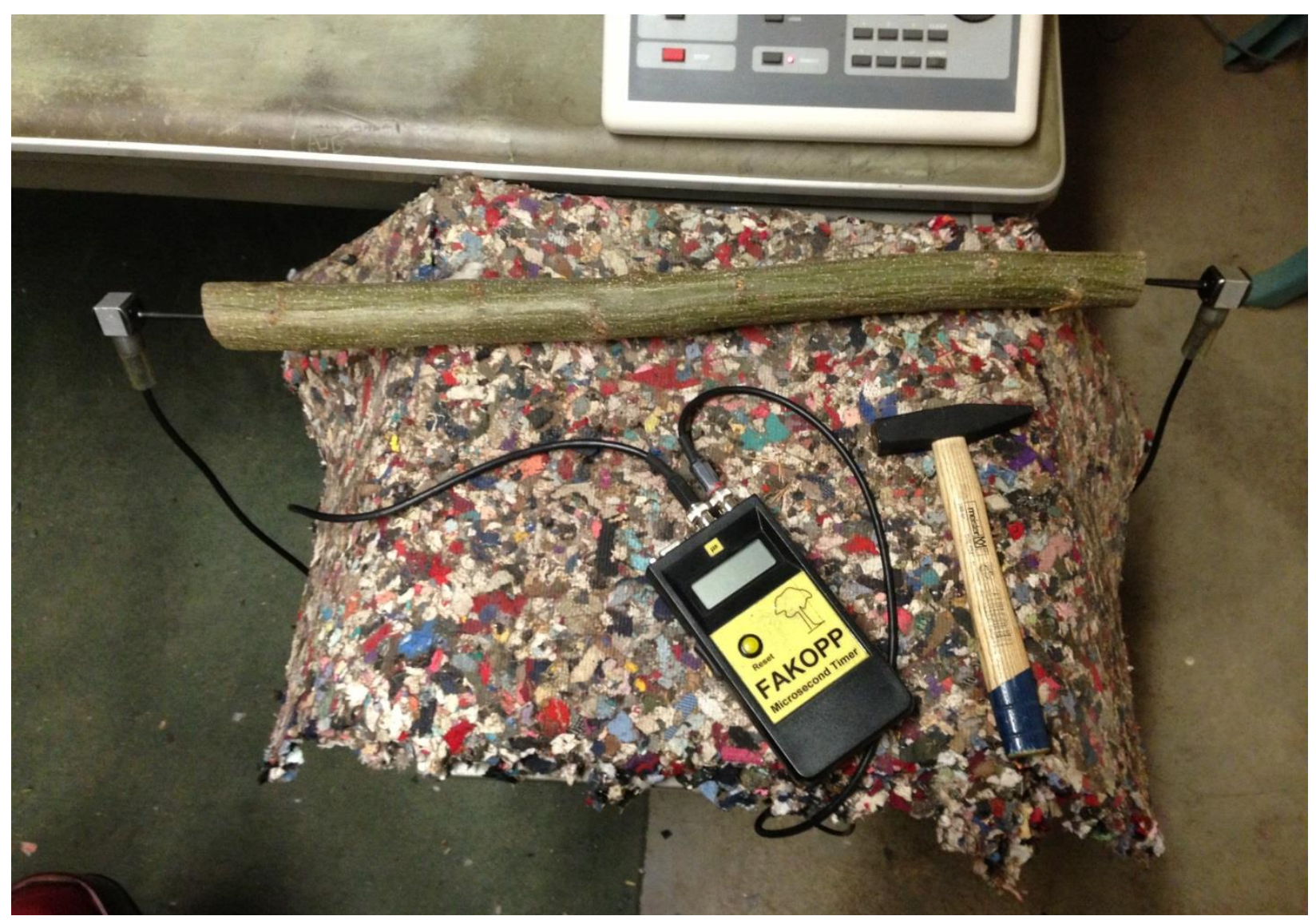

Figure 3.3: A stump sprout sample undergoing sound wave density testing by the Fakopp testing machine. This process was replicated five times per branch.

This was replicated five times per sample for each group following a protocol which suggested that measuring each sample with 3 hits at the same location would be sufficient in assessing different stands (Carter et al. 2005a; Carter et al. 2005b). The samples were then subjected to a three point bending test with a span of $44.45 \mathrm{~cm}$ using a universal test machine (UTM, Instron model MTS 810 ) at a rate of $0.16 \mathrm{~cm}$ per minute (Figure 3.4 and 3.5). 


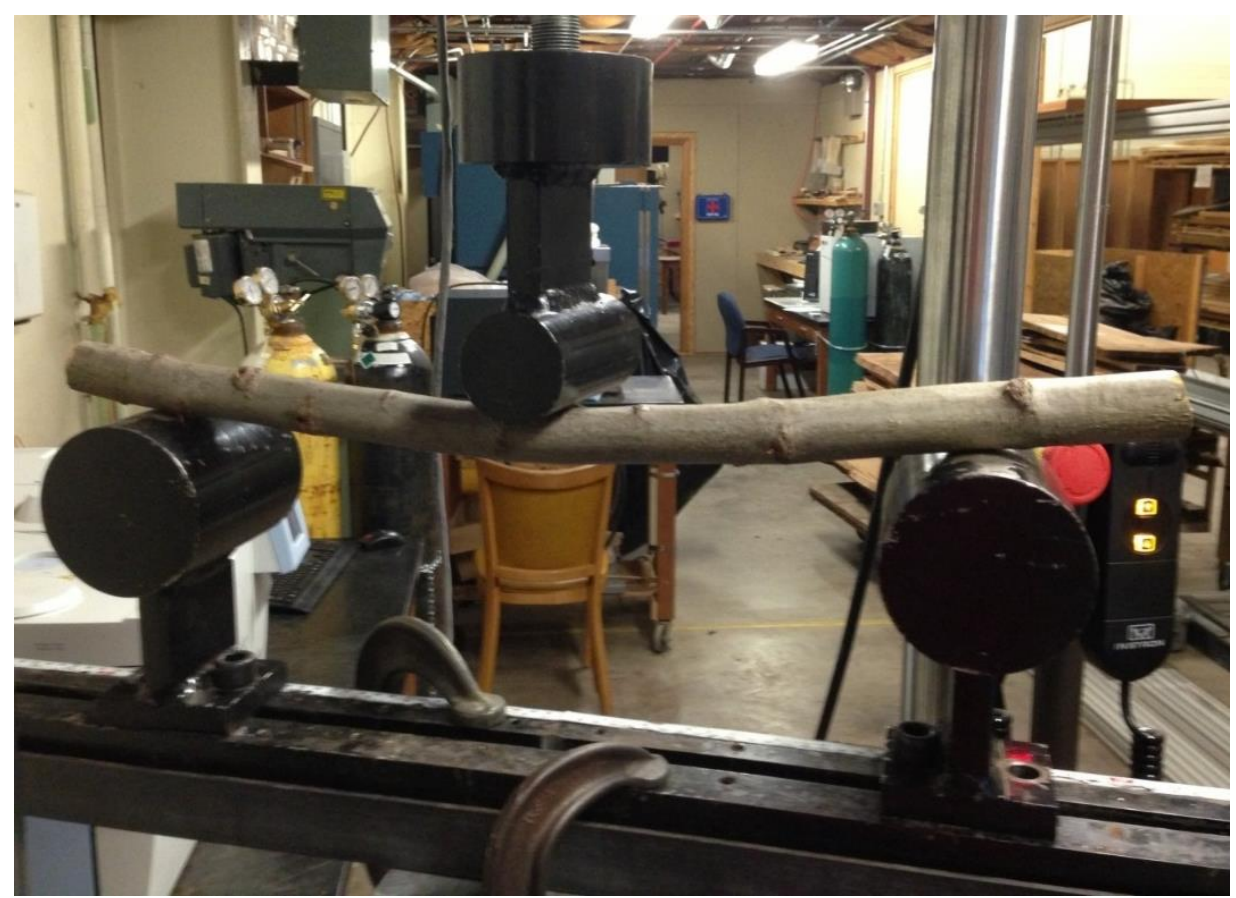

Figure 3.4: A stump sprout sample undergoing a three-point bending test by the Universal test machine testing machine.

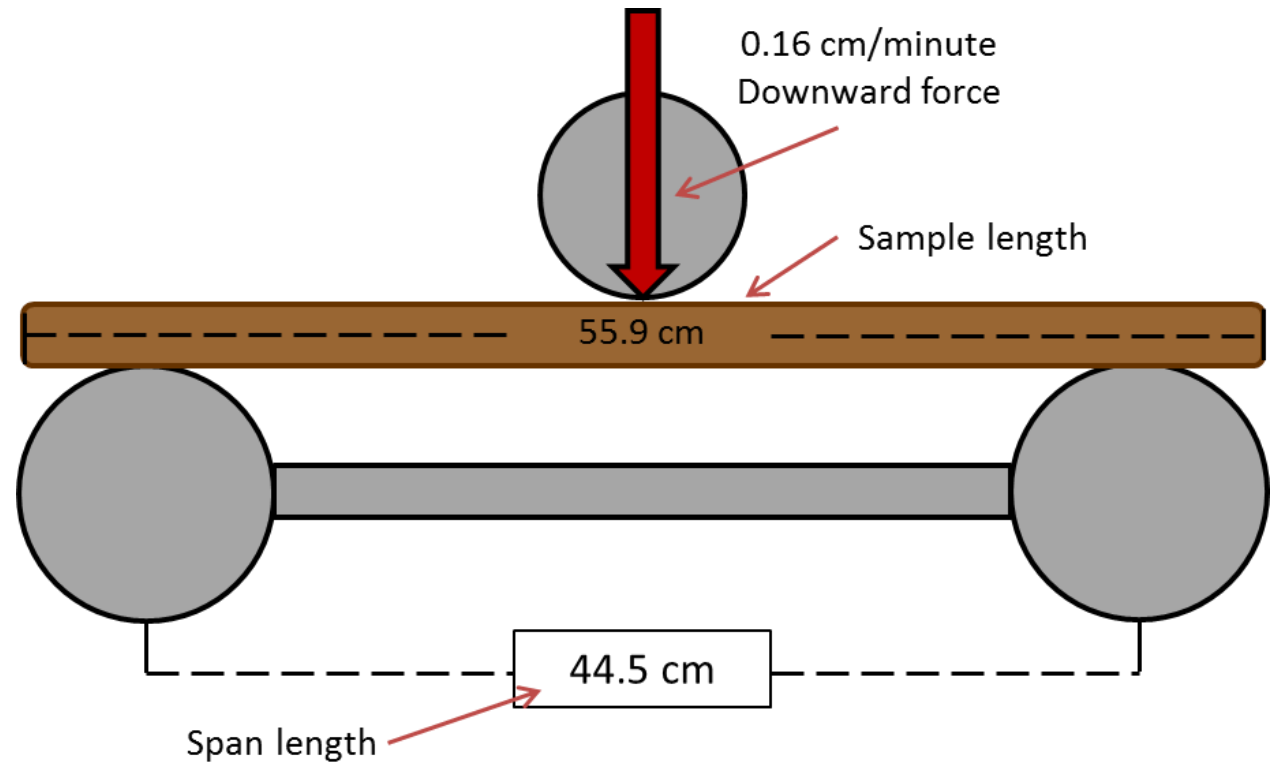

Figure 3.5: Example of the Universal test machine, 3-point bending test with downward force distance per time, sample length, and span length. 
The span/depth ratio was selected in accordance to a $14: 1 \mathrm{~cm}$ length to diameter ratio as presented in the ASTM D 198-05 for the universal test machine (ASTM 2005). Due to the high flexibility of the wood, loading was rarely able to be conducted beyond the yield point, thus only MOE was calculated.

Data from the Fakopp sound wave density instrument was put into the following equation to calculate $\mathrm{MOE}_{\mathrm{D}}$.

$$
M O E_{D}=c^{2} \times \rho,(\text { Equation } 1)
$$

Where:

- $M O E_{D}=$ dynamic modulus of elasticity in gigapascals $\left(\frac{n}{m^{2}}\right) \times 10^{9}$

- $\mathrm{c}=$ ultrasonic stress wave velocity $\left(\frac{\mathrm{cm}}{\mathrm{s}}\right)=$ transit distance $\left(\frac{(\mathrm{cm})}{(\mathrm{s})}\right)$

- $\rho=$ mass density $\left(\frac{\text { weight }(\mathrm{g})}{\text { force of gravity*volume }(\mathrm{cm})^{4}}\right)$

Slope was obtained from the deformation of the wood conducted using the UTM, was put into the following formula for elasticity:

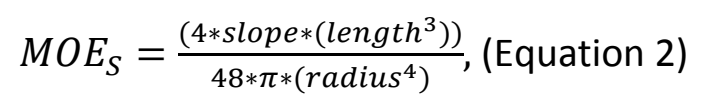

Where:

- $M O E_{s}=$ static modulus of elasticity in gigapascals $\left(\frac{n}{m^{2}}\right) \times 10^{9}$

- Length= is the overall length of the sample $(\mathrm{cm})$ 
- Radius= is the average radius of the overall sample taken at three points, large-end radius, middle radius, and small-end radius $(\mathrm{cm})$.

- Slope $=$ slope of the linear region taken from the force $(n)$ versus deflection $(\mu \mathrm{m})$ curve.

Immediately after samples were loaded using the UTM, cookies from the large end of the sample were cut and then weighed. These cookies were dried in a Fisher Scientific Isotemp 500 series oven at 50 Celsius for 3 days. Following the dry down period, the samples were immediately weighed and moisture content percent was calculated.

Moisture Content $\%$ at time of testing $=\frac{\text { wet weight-dryweight }}{\text { dryweigh }} * 100$, (Equation 3 ) Specific gravity is a unitless measurement and quantifies the amount of wood substance contained in a piece of wood.

Specific Gravity $=\frac{\text { Dry Weight }(g)}{\text { Fresh Volume }\left(\mathrm{cm}^{3}\right) * \text { Density of Water }\left(\frac{g}{\mathrm{~cm}^{3}}\right)},($ Equation 4)

Age was calculated for each branch based on visual counting of the growth rings at the large end. Statistical analysis including ANOVA, Welch's and paired t-tests and linear regression were conducted in R-studio software version 0.98 at $\alpha=0.05$. Statistical parameter data and residuals was tested and determined to be normal.

\section{Results:}

A total of 120 stump sprouts were removed during two different periods, 60 pre-dormant (2013) and 60 dormant (2012). The diameter for pre-dormant sprouts and dormant sprouts was 
significantly different $(P=<0.001, n=118$, Table 3.1), with pre-dormant having a larger average diameter.

Table 3.1: T-tests performed in identifying key statistical differences in specific branch attributes. P-values which are bold are significant at $\alpha=0.05$.

\begin{tabular}{ccc}
\multicolumn{3}{c}{ Welch's T-test } \\
\hline Diamater modeled by season & Mean \pm SE (cm) & P-value \\
Pre-Dormant (2013) & $3.62 \pm 0.04$ & $<0.001$ \\
Dormant (2012) & $3.28 \pm 0.03$ & \\
Age modeled by season & Mean \pm SE (yrs) & P-value \\
Pre-Dormant (2013) & $3.62 \pm 0.06$ & $<\mathbf{0 . 0 0 1}$ \\
Dormant (2012) & $2.98 \pm 0.04$ & \\
Diamater modeled by treatment & Mean \pm SE (cm) & P-value \\
Cold & $3.44 \pm 0.04$ & \\
Ambient & $3.45 \pm 0.05$ & 0.535
\end{tabular}

Ages ranged from 2-4 years between the two sample seasons, pre-dormancy and dormancy.

Average age was 3.3 years (Table 3.1). A Welch's t-test found a statistically significant difference between the ages of the dormant and pre-dormant season $(P=<0.001, n=120)$. The pre-dormant stage had a higher mean age (3.62) than the dormant stage (2.98) most likely explained by the time between sampling and incurrence of a growing season. Out of 120 samples, four were age 2 (3\%), 76 were age $3(63 \%)$, and 40 were age 4 (33\%) (Table 3.2). 
Table 3.2: Combined age distribution and age distribution by year.

\section{Combined Age Distribution}

\begin{tabular}{ccc} 
Sample Age & Number of Samples & Percent of Population \\
\hline 2 & 4 & $3 \%$ \\
3 & 76 & $63 \%$ \\
4 & 40 & $33 \%$ \\
\hline
\end{tabular}

Age Distribution by Year

\begin{tabular}{ccc} 
& \multicolumn{2}{c}{ Age Distribution by Year } \\
Yvear & Mean \pm SE & $\begin{array}{c}\text { Ave MOE } \pm \text { SE } \\
\text { (GPA) }\end{array}$ \\
\hline 2012 & & $1.24 \pm 0.03$ \\
$\begin{array}{c}\text { (Dormant) } \\
2013\end{array}$ & $3.62 \pm 0.06$ & \\
(Pre- & & $1.35 \pm 0.03$ \\
Dormant) & $2.98 \pm 0.04$ &
\end{tabular}

A paired t-test did not find a significant relationship between age for the UTM samples and MOE for both dormant and pre-dormant stages $(P=0.758, n=120)$. Additionally, age did not have a significant effect on elasticity data from the Fakopp samples for both dormant and predormant stages $(P=0.203, n=120)$ (Table 3.2).

Kretschmann (2010) lists specific gravity for northern red oak as being 0.56 for green wood. On average, the samples in this study were well above this specific gravity indicator with a mean specific gravity of 0.75 (Figure 3.6). 


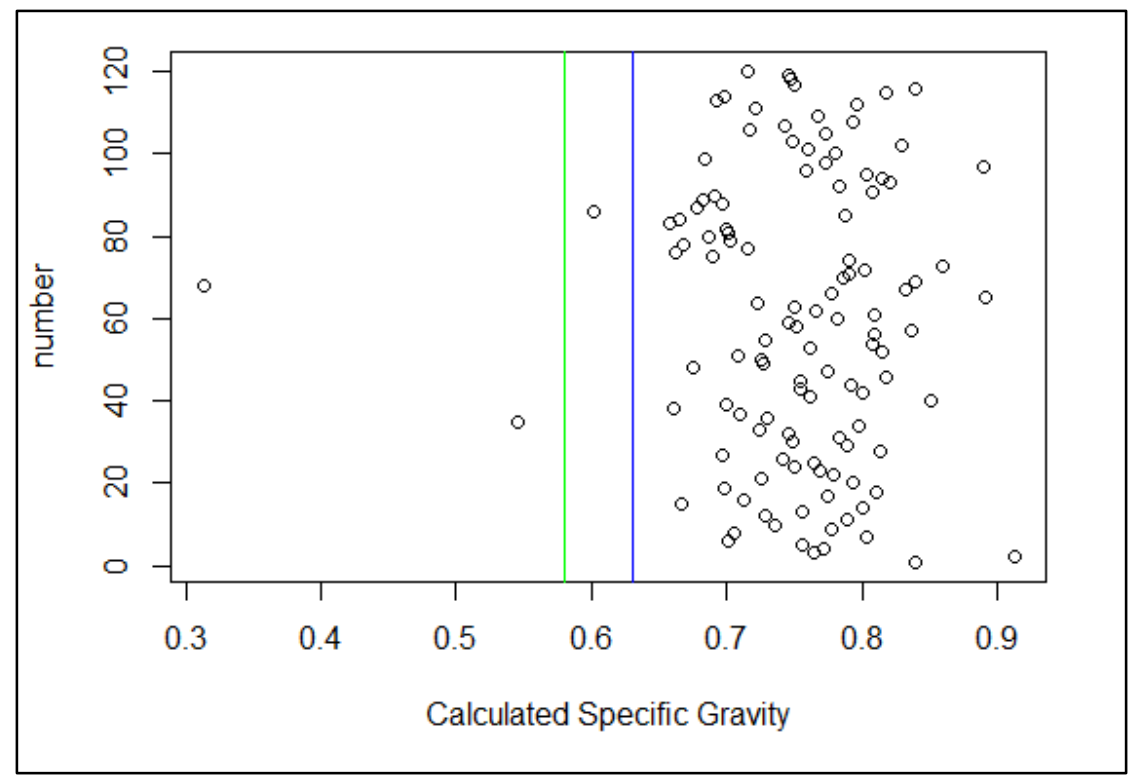

Figure 3.6: The calculated specific gravity for the seasonality study. The two lines indicate the specific gravities listed by Kretschmann (2010), where green is 0.58 and blue is 0.63 for northern red oak (Quercus rubra).

A paired student's t-test identified that there is a significant difference between MOE measured by UTM versus Fakopp ( $P=<0.001, n=120)$ showing that the Fakopp predicts a higher MOE (Table 3.3 and Figure 3.7). 


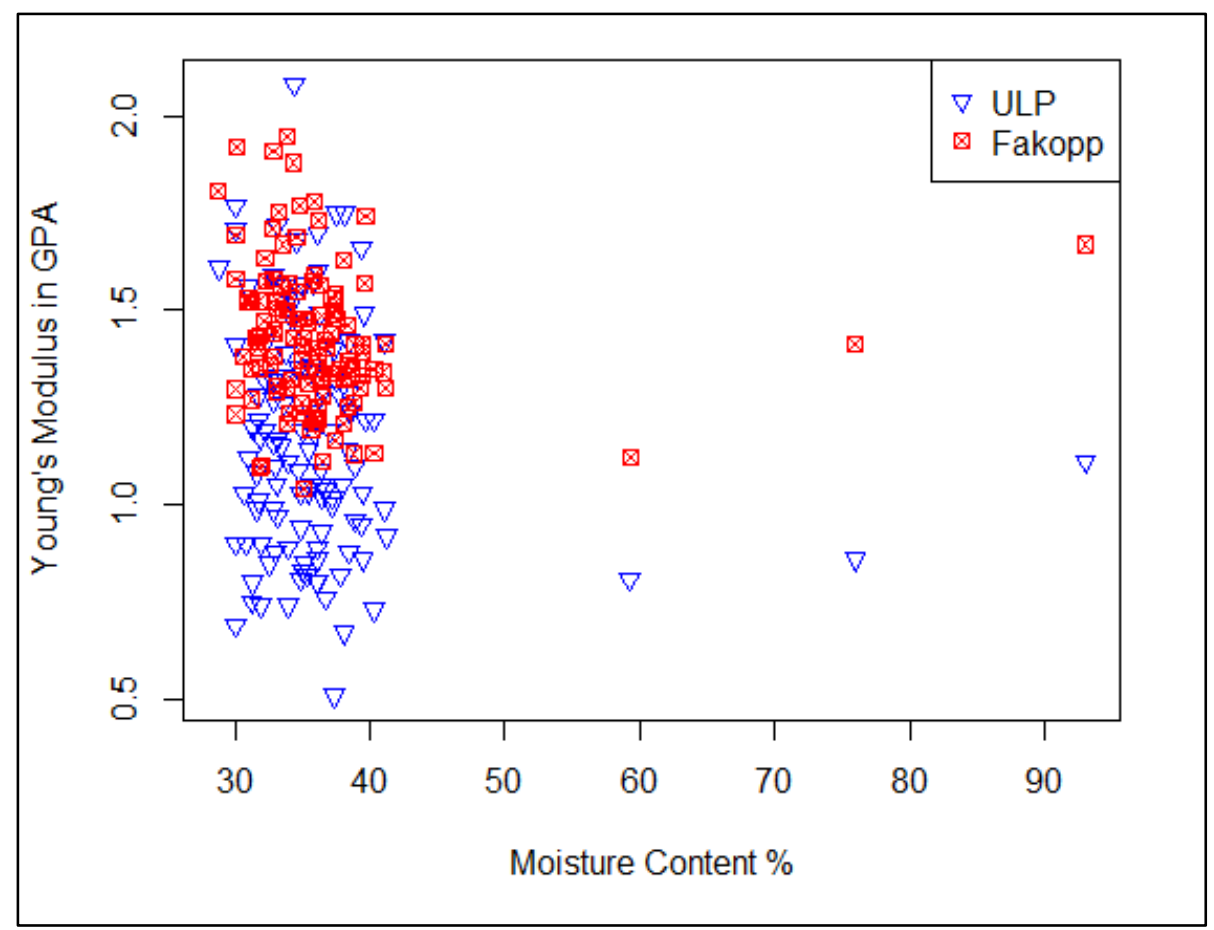

Figure 3.8: Flexure modulus calculations based on machine type and moisture content percent. Note that fiber saturation point is at $30 \%$ moisture content.

Additionally, a significant difference between the $M O E_{S}$ and $M O E_{D}$ can be seen when testing both the ambient $(P=<0.001, n=120)$ and cold $(P=<0.001, n=120)$ treatments separately (Table 3.3). 
Table 3.3: Paired t-tests identifying key differences between the universal test machine and Fakopp.

\begin{tabular}{|c|c|c|c|}
\hline \multicolumn{4}{|c|}{ ULP vs Fakopp } \\
\hline & Mean ( \pm SE) GPA & $\mathrm{n}$ & $\mathrm{p}$ value \\
\hline Pre-Dormant ULP & $1.07 \pm 0.04$ & \multirow{2}{*}{116} & \multirow{2}{*}{$<0.001$} \\
\hline Pre-Dormant Fakopp & $1.40 \pm 0.03$ & & \\
\hline Dormant ULP & $1.25 \pm 0.04$ & \multirow{2}{*}{120} & \multirow{2}{*}{$<0.001$} \\
\hline Dormant Fakopp & $1.44 \pm 0.02$ & & \\
\hline \multicolumn{4}{|c|}{ Temperature Effects } \\
\hline & Mean ( \pm SE) GPA & $\mathrm{n}$ & $p$ value \\
\hline Ambient ULP & $1.11 \pm 0.04$ & \multirow{2}{*}{116} & \multirow{2}{*}{$<0.001$} \\
\hline Ambient Fakopp & $1.34 \pm 0.03$ & & \\
\hline Cold ULP & $1.22 \pm 0.04$ & \multirow{2}{*}{120} & \multirow{2}{*}{$<0.001$} \\
\hline Cold Fakopp & $1.50 \pm 0.03$ & & \\
\hline
\end{tabular}

The effect of temperature on modulus of elasticity between the two seasons in the load press data was found to have significance $(P=0.048, n=118)$ with the cold treatment found to have a higher $\mathrm{MOE}_{\mathrm{s}}$ using a t-test (Table 3.4). 
Table 3.4: Paired t-test identifying differences within machine type (universal test machine and Fakopp).

\begin{tabular}{|c|c|c|c|c|c|c|c|}
\hline \multicolumn{4}{|c|}{ Universal Load Press } & \multicolumn{4}{|c|}{ Fakopp Sound Wave Density Meter } \\
\hline & Mean ( \pm SE) GPA & $\mathrm{n}$ & $\mathrm{p}$ value & & Mean $( \pm$ SE) GPA & $\mathrm{n}$ & $p$ value \\
\hline Dormant & $1.29 \pm 0.06$ & \multirow{2}{*}{118} & \multirow{2}{*}{$<0.001$} & Dormant & $1.44 \pm 0.02$ & \multirow{2}{*}{118} & \multirow{2}{*}{0.293} \\
\hline Pre-Dormant & $1.14 \pm 0.05$ & & & Pre-Dormant & $1.40 \pm 0.03$ & & \\
\hline \multicolumn{4}{|c|}{ Within Seasons } & \multicolumn{4}{|c|}{ Within Seasons } \\
\hline Dormant Cold & $1.29 \pm 0.06$ & \multirow{2}{*}{60} & \multirow{2}{*}{0.309} & Dormant Cold & $1.51 \pm 0.04$ & \multirow{2}{*}{60} & \multirow{2}{*}{0.004} \\
\hline Dormant Ambient & $1.21 \pm 0.05$ & & & Dormant Ambient & $1.38 \pm 0.03$ & & \\
\hline Pre-Dormant Cold & $1.14 \pm 0.05$ & \multirow{2}{*}{58} & \multirow{2}{*}{0.043} & Pre-Dormant Cold & $1.49 \pm 0.05$ & \multirow{2}{*}{58} & \multirow{2}{*}{0.003} \\
\hline Pre-Dormant Ambient & $1.00 \pm 0.05$ & & & Pre-Dormant Ambient & $1.31 \pm 0.05$ & & \\
\hline \multicolumn{2}{|c|}{ Between Seasons } & & & \multicolumn{4}{|c|}{ Between Seasons } \\
\hline Cold Dormant & $1.29 \pm 0.06$ & \multirow{2}{*}{60} & \multirow{2}{*}{0.059} & Cold Dormant & $1.51 \pm 0.04$ & \multirow{2}{*}{60} & \multirow{2}{*}{0.702} \\
\hline Cold Pre Dormant & $1.14 \pm 0.05$ & & & Cold Pre-Dormant & $1.49 \pm 0.04$ & & \\
\hline Ambient Dormant & $1.21 \pm 0.05$ & \multirow{2}{*}{58} & \multirow{2}{*}{0.003} & Ambient Dormant & $1.37 \pm 0.05$ & \multirow{2}{*}{58} & \multirow{2}{*}{0.208} \\
\hline Ambient Pre-Dormant & $1.00 \pm 0.05$ & & & Ambient Pre-Dormant & $1.31 \pm 0.03$ & & \\
\hline
\end{tabular}

A significant difference was found between the modulus of elasticity for the pre-dormancy and dormancy seasons $(P=<0.001, n=118)$ with the pre-dormant stage found to have a lower MOE. Yet there was not a significant interaction between temperature and season $(P=0.510, n$ = 120) Table 3.4 .

As in the $\mathrm{MOE}_{S}$ data, a One Way Anova identified that the cold samples had a higher $\mathrm{MOE}_{\mathrm{D}}$ than the ambient samples when using the Fakopp $(P=<0.001, n=118)$. The effect of season on the acoustic measurement of modulus of elasticity lacked significance $(P=0.293, n=120)$. Additionally, there was no significant interaction between temperature and season $\operatorname{MOE}_{\mathrm{D}}(P=$ 0.496, $n=120$ ) (Table 3.4).

Comparing the static and dynamic MOE data, a one way Anova found significant difference for the treatment on the combined season MOE data $(P=<0.001, n=236)$ with the cold treatment predicting a higher MOE. Additionally, a significant difference in modulus of elasticity was found 
for dormant versus pre-dormant when using the UTM compared to the Fakopp $(P=0.003, n=$ 236) with the UTM measuring elasticity lower GPA. There was no significant interaction between treatment and machine type $(P=0.409, n=236)$ (Table 3.5).

Table 3.5: Statistical parameters with the description of the test and the associated mean values attributes that are bolded are significant at $\alpha=0.05$.

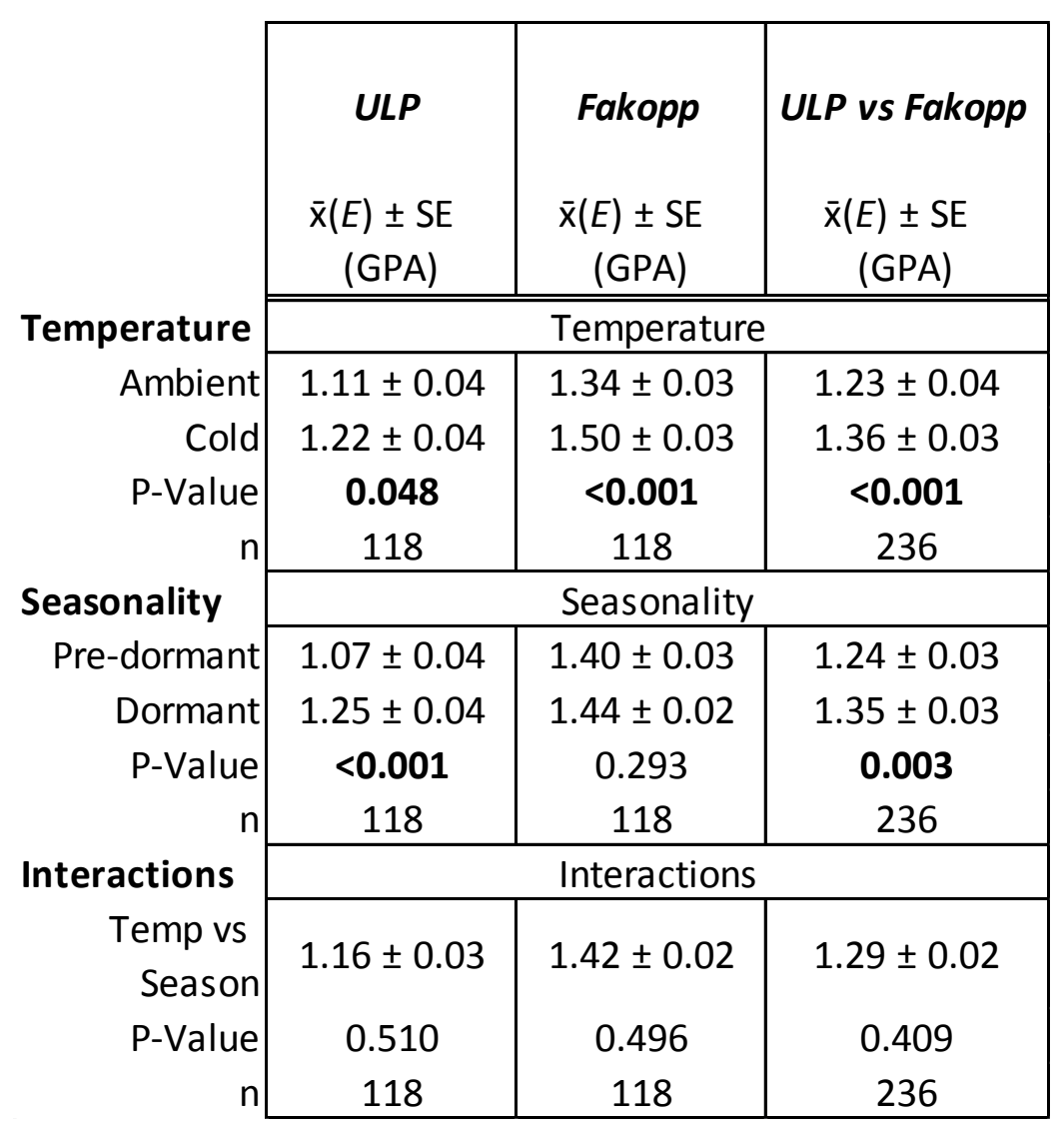

\section{Discussion:}

The literature suggests that outside temperature plays an important role on the modulus of elasticity of branch wood (Cannell and Morgan 1989; Despland and Houle 1997; Downes and Drew 2008; Gao et al. 2012; Gao et al. 2013). Outdoor temperature during the pre-dormant 
testing was 25 Celcius, while the outdoor temperature during dormant testing was -6.7 Celcius. Flexure modulus of elasticity can be defined as an object's tendency to be deformed elastically, or not permanently, when a force is applied to it. As temperatures decrease, branch wood tends to become more rigid causing a reduction in bending, (Gerhards 1982; Kretschmann 2010; Gao et al. 2012; Gao et al. 2013).

Trees are known to enter a dormant stage as climactic periodicity occurs; this is associated with the leaf senescence in many deciduous hardwood trees. Seasonal periodicity can be measured by the tree's physiological allocation of resources to the root system (Kozlowski and Pallardy 1997). Our research suggests that there is a difference between the modulus of elasticity of pre-dormancy and dormancy when testing $\mathrm{MOE}_{\mathrm{s}}$. The pre-dormant sprouts had a lower modulus of elasticity, despite being slightly older and larger than the dormant sprout. Thus predormant wood appears to have decreased wood rigidity that allows for increased bending. This is consistent with modulus of elasticity findings based on temperature for various species and specimen sizes (Gerhards 1982). The change in elasticity will allow increased bending in predormancy conditions which may be beneficial for a tree. If an unseasonal snow or ice storm occurs, the large amount of leaf area associated with pre-dormancy will intercept an increased static load than would be intercepted during dormancy. Yet, this static load would not dissipate as would be expected in dynamic loading; an increased stress could lead to larger strain resulting in more failures. Therefore, it could be that a higher MOE, which likely corresponds to a higher MOR, would be better to reduce failure. The development of models that predict branch failures could help the Arboricultural community understand which branches are more prone to failures. These models would need to include various inputs including branch 
allometry, axial and radial variations in material properties, amount of leaf area, and the added load due to static or dynamic loading. While there is a growing body of knowledge in many of these areas, the literature does not appear to address how much ice or snow can build up on a branch and the subsequent load and bending moments that are applied.

When testing for treatment, half of the northern red oak samples were cooled to -6.7 Celsius while the other half were kept at ambient room temperature or 21.1 Celsius. As a baseline test, our research suggests that colder temperatures result in a slightly higher MOE when using the UTM. It is not known if this increase will result in a meaningful increase in modulus of rupture and overall failures.

Our research also suggests that there is a difference in the cold and ambient treatment on modulus of elasticity when testing with the FAKOPP sound wave meter. The results indicated that the cold treatment had generally larger modulus of elasticity resulting in an increased rigidity. This is consistent with findings that indicate when wood temperature is below freezing, there is a continual increase of acoustic velocity, while the inverse can be seen as the wood warms above freezing temperatures (Gao et al. 2012). This phenomenon can be observed in other naturally occurring materials such as rocks and manmade materials such as aluminum (Timur 1977; Fukuhara and Yamauchi 1993).

Our research suggests that there is a difference in testing with the universal test machine and the FAKOPP sound wave meter. On average, the UTM calculates modulus of elasticity lower than the sound wave meter in frozen samples. This may be attributed to the effect of the frozen wood on the speed of sound through the branch sample, therefore the sound wave meter will 
likely overestimate MOE if tested in colder weather. A test comparing the UTM and the Fakopp during ambient temperatures determined that there is statistical difference between the means of MOE for each machine, again with the UTM predicting MOE lower than the Fakopp.

More tests should be conducted to determine if there is a good cut off temperature when using stress wave velocity meters. Since sound wave testing does not require destructive sampling it is worth determining if a model can be developed to correct for temperature making the technology more applicable in any climate or time of year. Additionally, the sound wave meter had a lower standard error than when using the UTM which makes this a desirable method for calculating branch rigidity. Future research should address the opportunity to create a model which can accurately predict MOE from sound wave density data that will be as accurate as conducting destructive sampling.

Additional research should be conducted as the stump sprouts age. In this research, the sprouts were between 2-4 years based on visual inspection of tree growth rings. Flexure modulus tests should be conducted as the wood ages to be able to model the transition in wood material properties. It has been shown that watersprouts are weaker than natural growing lateral branches (Dahle et al. 2006). The strength difference could be due to material properties as well as the lack of a branch collar. It is likely that any difference in material properties is due to the inherent variation between juvenile and mature wood. Instruments such as the FAKOPP sound wave meter could be used to measure MOE during sprout development in a nondestructive manner. 
This study did not measure or test the significance of height of the stump sprout or cardinal direction. These may be significant factors when researching the interaction between sunlight and the availability of resources on Flexure modulus.

\section{Implications:}

The knowledge from this seasonality research can help urban forest managers and arborists understand how static loading events can affect branches differently based on timing of storm events. For example, pre-dormant wood tends to be less rigid allowing for increased bending which can cause a failure during an unseasonal winter storm, either late in the fall prior to leaf drop or in the early spring when leaves are developing. We can then postulate that dormant wood has physiologically developed to be stiffer based on the increase of loading from winter storms compared to summer storms. Additionally, this research provides information that acoustic sound wave may be an inexpensive and portable means of testing modulus of elasticity in a live tree but is affected by freezing temperatures and is not as accurate as utilizing destructive sampling. With future research of this technology could be used as a way of calculating branch rigidity. 


\section{References:}

ASTM (2005). "Standard Test Methods of Static Tests of Lumber in Structural Sizes." D198(05): 20.

Bächle, H. and J. Walker (2006). "The influence of temperature on the velocity of sound in green pine wood." European Journal of Wood and Wood Products 64(5): 429-430.

Bao, F., Z. Jiang, et al. (2001). "Differences in wood properties between juvenile wood and mature wood in 10 species grown in China." Wood Science and Technology 35(4): 363-375.

Bertram, J. E. A. (1989). "Size-dependent differential scaling in branches: the mechanical design of trees revisited." Trees-Structure and Function 3(4): 241-253.

Boedhram, N., T. J. Arkebauer, et al. (2001). "Season-long characterization of vertical distribution of leaf area in corn." Agronomy Journal 93(6): 1235-1242.

Cannell, M. and J. Morgan (1987). "Young's modulus of sections of living branches and tree trunks." Tree Physiology 3(4): 355-364.

Cannell, M. and J. Morgan (1989). "Branch breakage under snow and ice loads." Tree Physiology 5(3): 307-317.

Carter, P., D. Briggs, et al. (2005a). "Acoustic testing to enhance western forest values and meet customer wood quality needs." Productivity of western forests: A forest products focus. Gen Tech Rep PNW-GTR-642. USDA For Serv Pacific Northwest Research Station, Portland, OR: 121129.

Carter, P., X. Wang, et al. (2005b). NDE of logs and standing trees using new acoustic tools: technical application and results. Proceedings of the 14th International Symposium on Nondestructive Testing of Wood.

Changnon, S. A. (2003). "Characteristics of ice storms in the United States." Journal of Applied Meteorology 42(5).

Chauhan, S. and J. Walker (2006). "Variations in acoustic velocity and density with age, and their interrelationships in radiata pine." Forest Ecology and Management 229(1): 388-394.

Dahle, G. A. and J. C. Grabosky (2009). "Review of literature on the function and allometric relationships of tree stems and branches." Journal of Arboriculture 35(6): 311.

Dahle, G. A. and J. C. Grabosky (2010a). "Allometric patterns in Acer platanoides (Aceraceae) branches." Trees-Structure and Function 24(2): 321-326.

Dahle, G. A. and J. C. Grabosky (2010b). "Variation in modulus of elasticity ( E) along Acer platanoides L.(Aceraceae) branches." Urban Forestry \& Urban Greening 9(3): 227-233.

Despland, E. and G. Houle (1997). "Climate influences on growth and reproduction of Pinus banksiana (Pinaceae) at the limit of the species distribution in eastern North America." American Journal of Botany 84(7): 928-928.

DeVallance, D. B., J. W. Funck, et al. (2011). "Evaluation of laminated veneer lumber tensile strength using optical scanning and combined optical-ultrasonic techniques." Wood and Fiber Science 43(2): 169-179.

Downes, G. and D. Drew (2008). "Climate and growth influences on wood formation and utilisation." Southern Forests: a Journal of Forest Science 70(2): 155-167.

Dwyer, J. F., E. G. McPherson, et al. (1992). "Assessing the benefits and costs of the urban forest." Journal of Arboriculture 18: 227-227.

Ewers, F. W. (1985). "Xylem structure and water conduction in conifer trees, dicot trees, and lianas." International Association of Wood Anatomists Bulletin 6(4).

Farnsworth, K. and K. Niklas (1995). "Theories of optimization, form and function in branching architecture in plants." Functional Ecology (United Kingdom). 
Field, C., V. Barros, et al. (2014). "Climate change 2014: impacts, adaptation, and vulnerability." Volume I: Global and Sectoral Aspects. Contribution of Working Group II to the Fifth Assessment Report of the Intergovernmental Panel on Climate ChangeCambridge University Press, Cambridge and New York.

Field, C. B., V. Barros, et al. (2012). Managing the Risks of Extreme Events and Disasters to Advance Climate Change Adaptation: Special Report of the Intergovernmental Panel on Climate Change, Cambridge University Press.

Fukuhara, M. and I. Yamauchi (1993). "Temperature dependence of the elastic moduli, dilational and shear internal frictions and acoustic wave velocity for alumina, $(Y)$ TZP and $\beta^{\prime}$-sialon ceramics." Journal of materials science 28(17): 4681-4688.

Gao, S., X. Wang, et al. (2013). Effect of Temperature and Moisture State Changes on Modulus of Elasticity of Red Pine Small Clear Wood. Series: Conference Proceedings.

Gao, S., X. Wang, et al. (2012). "Effect of temperature on acoustic evaluation of standing trees and logs: Part 1-Laboratory investigation." Wood and Fiber Science 44(3): 286-297.

Gartner, B. L., S. H. Bullock, et al. (1990). "Water transport properties of vine and tree stems in a tropical deciduous forest."

Genet, A., D. Auty, et al. (2013). "Consequences of faster growth for wood density in northern red oak (Quercus rubra Liebl.)." Forestry 86(1): 99-110.

Gerhards, C. C. (1982). "Effect of moisture content and temperature on the mechanical properties of wood: an analysis of immediate effects." Wood and Fiber Science 14(1): 4-36.

Gilbert, E. A. and E. T. Smiley (2004). "Picus Sonic Tomography for the Quanification of Decay in White Oak (Quercus alba) and Hickory (Carya spp.)." Journal of Arboriculture 30(5): 277-281.

Gilman, E. F. (2002). Tree Pruning, Intl Society of Arboriculture.

Gower, S. T. (2003). "Patterns and Mechanisms of the Forest Carbon Cycle 1." Annual Review of Environment and Resources 28(1): 169-204.

Hacke, U. G., J. S. Sperry, et al. (2001). "Trends in wood density and structure are linked to prevention of xylem implosion by negative pressure." Oecologia 126(4): 457-461.

Halabe, U. B., G. M. Bidigalu, et al. (1997). "Nondestructive evaluation of green wood using stress wave and transverse vibration techniques." Materials evaluation 55(9): 1013-1018.

Harris, R. W. (1992). Arboriculture: integrated management of landscape trees, shrubs, and vines, Prentice-Hall International.

Hauer, R. J., J. O. Dawson, et al. (2006). "Trees and ice storms: The development of ice storm-resistant urban tree populations."

Hauer, R. J., W. Wang, et al. (1993). "Ice storm damage to urban trees." Journal of Arboriculture 19: 187187.

Helińska-Raczkowska, L. (1994). Variation of vessel lumen diameter in radial direction as an indication of the juvenile wood growth in oak (Quercus petraea Liebl). Annales des sciences forestières, EDP Sciences.

Henneke, E. G., W. W. Stinchcomb, et al. (1986). Ultrasonic stress wave characterization of composite materials, Virginia Polytechnic Institute and State University Blacksburg Department of Engineering Science and Mechanics.

Hibbeler, R. (2000). "Mechanics of Materials-Prentice Hall." Inc., New Jersey: 120-135.

Hogan, C. J. and K. J. Niklas (2004). "Temperature and water content effects on the viscoelastic behavior of Tilia americana (Tiliaceae) sapwood." Trees 18(3): 339-345.

James, K. R., G. A. Dahle, et al. (2014). "Tree Biomechanics Literature Review: Dynamics." Arboriculture \& Urban Forestry 40(1).

Kaeiser, M. and S. G. Boyce (1965). "The relationship of gelatinous fibers to wood structure in eastern cottonwood (Populus deltoides)." American Journal of Botany: 711-715. 
Konijnendijk, C. C., R. M. Ricard, et al. (2006). "Defining urban forestry-A comparative perspective of North America and Europe." Urban Forestry \& Urban Greening 4(3): 93-103.

Kozlowski, T. and S. Pallardy (1997). "Physiology of Woody Plants. Academic Press." San Diego.

Kretschmann, D. E. (2010). "Mechanical properties of wood." Environments 5: 34.

Landau, L. D., E. Lifshitz, et al. (2009). "Theory of elasticity: Vol. 7 of course of theoretical physics." Physics Today 13(7): 44-46.

Markwardt, L. J. and T. R. C. Wilson (1935). Strength and related properties of woods grown in the United States, US Government Printing Office.

McLean, J. P., T. Zhang, et al. (2011). "The decreasing radial wood stiffness pattern of some tropical trees growing in the primary forest is reversed and increases when they are grown in a plantation." Annals of forest science 68(4): 681-688.

McMahon, T. A. and R. E. Kronauer (1976). "Tree structures: Deducing the principle of mechanical design." Journal of Theoretical Biology 59(2): 443-466.

Niklas, K. J. (1992). Plant biomechanics: an engineering approach to plant form and function, University of Chicago Press.

Niklas, K. J. (1997). "Size-and age-dependent variation in the properties of sap-and heartwood in Black Locust (Robinia pseudoacacia L.)." Annals of Botany 79(5): 473-478.

Niklas, K. J. (1999). "A mechanical perspective on foliage leaf form and function." New Phytologist 143(1): 19-31.

Niklas, K. J. (2000). "Computing factors of safety against wind-induced tree stem damage." Journal of Experimental Botany 51(345): 797-806.

Niklas, K. J. (2007). "Maximum plant height and the biophysical factors that limit it." Tree physiology 27(3): 433-440.

Niklas, K. J. and H. C. Spatz (2000). "Wind-induced stresses in cherry trees: evidence against the hypothesis of constant stress levels." Trees-Structure and Function 14(4): 230-237.

Nowak, D. J., S. M. Stein, et al. (2010). Sustaining America's Urban Trees and Forests, United States Department of Agriculture, Forest Service, Northern Research Station.

Nowak, D. J. and J. T. Walton (2005). "Projected Urban Growth (20002050) and Its Estimated Impact on the US Forest Resource." Journal of Forestry 103(8): 383-389.

Nykänen, M.-L., H. Peltola, et al. (1997). "Factors affecting snow damage of trees with particular reference to European conditions."

Panshin, A. (1980). "C. deZeeuw. 1980." Textbook of wood technology. 4th Ed McGraw-Hill, New York, $\underline{N Y}$.

Plomion, C., G. Leprovost, et al. (2001). "Wood formation in trees." Plant physiology 127(4): 1513-1523.

Read, J. and A. Stokes (2006). "Plant biomechanics in an ecological context." American Journal of Botany 93(10): 1546-1565.

Ross, R. J., K. A. MCDONALD, et al. (1997). "Relationship between log and lumber modulus of elasticity." Forest Products Journal 47(2): 89.

Schmidt, R. and J. Pomeroy (1990). "Bending of a conifer branch at subfreezing temperatures: implications for snow interception." Canadian Journal of Forest Research 20(8): 1251-1253.

Smiley, E. T., N. P. Matheny, et al. (2011). Tree Risk Assessment, International Society of Arboriculture.

Spatz, H.-C. and F. Bruechert (2000). "Basic biomechanics of self-supporting plants: wind loads and gravitational loads on a Norway spruce tree." Forest Ecology and Management 135(1-3): 33-44.

Spicer, R. and B. Gartner (1998). "How does a gymnosperm branch (Pseudotsuga menziesii) assume the hydraulic status of a main stem when it takes over as leader?" Plant, Cell \& Environment 21(10): 1063-1070.

Spicer, R. and B. L. Gartner (1998). "Hydraulic properties of Douglas-fir (Pseudotsuga menziesii) branches and branch halves with reference to compression wood." Tree Physiology 18(11): 777-784. 
Stephenson, N., A. Das, et al. (2014). "Rate of tree carbon accumulation increases continuously with tree size." Nature.

Timur, A. (1977). "Temperature dependence of compressional and shear wave velocities in rocks." Geophysics 42(5): 950-956.

Valinger, E., L. Lundqvist, et al. (1995). "Mechanical bending stress applied during dormancy and (or) growth stimulates stem diameter growth of Scots pine seedlings." Canadian Journal of Forest Research 25(6): 886-890.

Vary, A. and K. J. Bowles (1979). "An ultrasonic-acoustic technique for nondestructive evaluation of fiber composite quality." Polymer Engineering \& Science 19(5): 373-376.

Vary, A. and R. Lark (1978). "Correlation of fiber composite tensile strength with the ultrasonic stress wave factor."

Wagner, K. R., F. W. Ewers, et al. (1998). "Tradeoffs between hydraulic efficiency and mechanical strength in the stems of four co-occurring species of chaparral shrubs." Oecologia 117(1-2): 5362.

Wang, X. and R. B. Allison (2008). "Decay detection in red oak trees using a combination of visual inspection, acoustic testing, and resistance microdrilling." Arboriculture and Urban Forestry 34(1): 1.

Williamson, G. B. (1984). "Gradients in wood specific gravity of trees." Bulletin of the Torrey Botanical Club: 51-55.

Woodrum, C. L., F. W. Ewers, et al. (2003). "Hydraulic, biomechanical, and anatomical interactions of xylem from five species of Acer (Aceraceae)." American Journal of Botany 90(5): 693-699.

Zobel, B. and J. R. Sprague (1998). "Juvenile wood in forest trees." 


\section{Acknowledgements:}

I would like to thank Dr. Greg Dahle my principal advisor for guidance and motivation, Dr. David DeVallance for help with wood mechanics and engineering principals, and Dr. Jingjing Liang, and Dr. Mo Zhou for assisting with statistics.

I would like to thank Jacob Berl for startup knowledge in R Studio statistical software, Justine Whitaker for help with going over presentation data related to this thesis and sampling during the "Seasonal Transitions of Flexure Modulus in Living Branch Wood," Darren Wood for being a motivating office mate, and Joey Plutro for assistance with climbing and cutting samples during the "Flexure Modulus Variations Distally along the Branch."

A special thanks to James V. Watson III for help with collecting data on both research studies, going over presentation data related to this thesis, and general help and friendship during my graduate studies. I would also like to thank the Watson family for support throughout my time at West Virginia University.

I would like to give thanks to Ron Carpenter, Terra Carpenter, Amanda Carpenter, Jerad Horning, and Carl Tucker, my family, for support during the time I was conducting research for this thesis. They have always been there whenever I have needed them.

Finally, I would like to thank the US Forest Service for funding these studies through the McIntire-Stennis grant as well as the Division of Forestry and Natural Resources at West Virginia University. 